NBER WORKING PAPER SERIES

UNCOVERED INTEREST PARITY AND MONETARY POLICY NEAR AND FAR FROM THE ZERO LOWER BOUND

\author{
Menzie D. Chinn \\ Yi Zhang \\ Working Paper 21159 \\ http://www.nber.org/papers/w21159
}

\author{
NATIONAL BUREAU OF ECONOMIC RESEARCH \\ 1050 Massachusetts Avenue \\ Cambridge, MA 02138
}

May 2015

We thank Charles Engel, Kenneth D. West, Kurt G. Lunsford, and Chenxin Liu for helpful comments, and faculty research funds of the University of Wisconsin-Madison for financial support. All remaining errors are solely our responsibility. The views expressed herein are those of the authors and do not necessarily reflect the views of the National Bureau of Economic Research.

NBER working papers are circulated for discussion and comment purposes. They have not been peerreviewed or been subject to the review by the NBER Board of Directors that accompanies official NBER publications.

(C) 2015 by Menzie D. Chinn and Yi Zhang. All rights reserved. Short sections of text, not to exceed two paragraphs, may be quoted without explicit permission provided that full credit, including $\odot$ notice, is given to the source. 
Uncovered Interest Parity and Monetary Policy Near and Far from the Zero Lower Bound Menzie D. Chinn and Yi Zhang

NBER Working Paper No. 21159

May 2015

JEL No. E12,F21,F31,F41,F47

\begin{abstract}
$\underline{\text { ABSTRACT }}$
Relying upon a standard New Keynesian DSGE, we propose an explanation for two empirical findings in the international finance literature. First, the unbiasedness hypothesis - the proposition that expost exchange rate depreciation matches interest differentials - is rejected much more strongly at short horizons than at long. Second, even at long horizons, the unbiasedness hypothesis tends to be rejected when one of the currencies has experienced a long period of low interest rates, such as in Japan and Switzerland. Using a calibrated New Keynesian dynamic stochastic general equilibrium model, we show how a monetary policy rule can induce the negative (positive) correlation between depreciation and interest differentials at short (long) horizons. The tendency to reject unbiasedness for Japan and Switzerland even at long horizons we attribute to the interaction of the monetary reaction function and the zero lower bound.
\end{abstract}

Menzie D. Chinn

Department of Economics

University of Wisconsin

1180 Observatory Drive

Madison, WI 53706

and NBER

mchinn@lafollette.wisc.edu

Yi Zhang

University of Wisconsin-Madison

Department of Economics

1180 Observatory Drive

Madison, WI 53706

yzhang237@wisc.edu 


\title{
Uncovered Interest Parity and Monetary Policy Near and Far from the Zero Lower Bound*
}

\author{
Menzie D. Chinn ${ }^{\dagger} \quad$ Yi Zhang ${ }^{\ddagger}$
}

May 14, 2015

\begin{abstract}
Relying upon a standard New Keynesian DSGE, we propose an explanation for two empirical findings in the international finance literature. First, the unbiasedness hypothesis - the proposition that expost exchange rate depreciation matches interest differentials - is rejected much more strongly at short horizons than at long. Second, even at long horizons, the unbiasedness hypothesis tends to be rejected when one of the currencies has experienced a long period of low interest rates, such as in Japan and Switzerland. Using a calibrated New Keynesian dynamic stochastic general equilibrium model, we show how a monetary policy rule can induce the negative (positive) correlation between depreciation and interest differentials at short (long) horizons. The tendency to reject unbiasedness for Japan and Switzerland even at long horizons we attribute to the interaction of the monetary reaction function and the zero lower bound.
\end{abstract}

JEL classification: E12, F21, F31, F41, F47

Keywords: uncovered interest parity, unbiasedness hypothesis, rational expectations, exchange rates, zero lower bound, New Keynesian model

\section{Introduction}

One of the most enduring empirical regularities in the international finance literature is the rejection of the joint hypothesis of uncovered interest rate parity (UIP) and rational expectations. According to the unbiasedness hypothesis, the interest rate differential between two countries should be an unbiased predictor of the change in the exchange rate between them. Chinn and Meredith (2004) document the continued failure of the unbiasedness hypothesis to hold for horizons of up to a year.

\footnotetext{
${ }^{*}$ We thank Charles Engel, Kenneth D. West, Kurt G. Lunsford, and Chenxin Liu for helpful comments, and faculty research funds of the University of Wisconsin for financial support. All remaining errors are solely our responsibility.

${ }^{\dagger}$ Robert M. La Follette School of Public Affairs; and Department of Economics, University of Wisconsin-Madison, 1180 Observatory Drive, Madison, WI 53706, USA; and NBER, USA. E-mail: mchinn@lafollette.wisc.edu

${ }^{\ddagger}$ Department of Economics, University of Wisconsin-Madison, 1180 Observatory Drive, Madison, WI 53706, USA. E-mail: yzhang237@wisc.edu
} 
But they also document that at horizons of greater than a year, the unbiasedness hypothesis holds better, so that at the ten year horizon, the hypothesis cannot be rejected.

Chinn and Quayyum (2013) update the results in Chinn and Meredith, using data ranging up to 2012. They confirm the finding that unbiasedness holds better at longer horizons than at short.

Chinn and Meredith attribute their finding to the greater endogeneity of the short term rate, given a Taylor-rule type central bank reaction function. They demonstrate that a Keynesian model incorporating sticky prices and model consistent expectations and importantly a random shock in the uncovered interest parity relation can replicate the pattern of unbiasedness rejections.

One key difference between the findings using the shorter and longer sample periods is that in the sample encompassing the Great Recession, and the encounter with the zero lower bound (ZLB), the tendency to reject the unbiasedness, even at the long horizon, increases. Even before the onset of the financial crisis, several countries had short term interest rates near the zero interest bound. Perhaps more importantly for our results, long term interest rates were particularly quite low in Japan and Switzerland, two currencies for which the estimated is noticeably low.

At first glance, there is no particular reason why the unbiasedness hypothesis should not hold when short and/or long term rates strike the zero interest bound, as expected exchange rate changes could adjust to make the parity condition hold. However, it seems worthwhile to investigate the sensitivity of the estimates to inclusion of the low-interest rate period. We arbitrarily define 1996Q1 as the low interest rate period for these two countries. Estimating the Fama regression on long horizon data, allowing for a slope break at 1996Q1, indicates that post-1996 the unbiasedness relationship breaks down, with the slope coefficient significantly different and negative in the latter period.

The advent of low long term interest rates in Japan and Switzerland is associated with the attenuation of evidence for the unbiasedness hypothesis at the long horizon for currency pairs involving these countries. However, it is not an explanation, as uncovered interest parity is an arbitrage condition.

There are two key motivations for this paper. The first is to show that a conventional New Keynesian dynamic stochastic general equilibrium (DSGE) model can yield the implication that under normal conditions, the long horizon Fama coefficient is positive, and greater than the short horizon coefficient (which is typically negative) with only a minor modification. The second is to demonstrate that when there is a substantial likelihood of encountering the zero lower bound (ZLB), the long horizon Fama coefficient will be lower.

In the next section we briefly review unbiasedness hypothesis and new empirical results. In Section 3, the model derivation is presented, and summarized in Section 3.11. In Section 4, the model calibration is shown. Sections 5 and 6 present, respectively, the calibration results without and with the zero lower bound. Section 7 concludes.

\section{Theory and Literature}

The UIP hypothesis states, if investors are risk neutral, and there are no barriers to cross-border capital flows, then the return from investing a unit amount in a risk free bond in the home currency for period $\mathrm{k}, i_{t, k}$, should equal the expected return from converting the unit amount into foreign 
currency and investing in risk free bond in foreign currency for period $\mathrm{k}$, and converting the foreign currency return back into home currency after period $\mathrm{k}$.

$$
E_{t} s_{t+k}-s_{t}=\left(i_{t, k}-i_{t, k}^{*}\right)
$$

Obviously, this hypothesis is difficult to test since the market's subjective expectation of the exchange rate is unobservable. The typical recourse adopted by researchers is to adopt the rational expectations hypothesis, so that the subjective market expectation equals the mathematical (conditional) expectation. Under the rational expectations hypothesis, the actual value of the future spot rate equals the expected value of future spot rate plus an error term,

$$
s_{t+k}=E_{t} s_{t+k}+\varepsilon_{t+k}
$$

where $\varepsilon_{t+k}$ is an expectation error that is orthogonal to everything that is known at time t. This yields:

$$
s_{t+k}-s_{t}=\left(i_{t, k}-i_{t, k}^{*}\right)+\varepsilon_{t+k}
$$

The resulting unbiasedness hypothesis is usually tested using the following specification, often referred to as the Fama regression (Fama, 1984):

$$
s_{t+k}-s_{t}=\alpha+\beta\left(i_{t, k}-i_{t, k}^{*}\right)+\zeta_{t+k}
$$

where the expected value of $\beta$ according to the hypothesis is 1 . The maintained hypothesis is the null hypothesis, and under the unbiasedness null, the error $\zeta_{t+k}$ is merely the expectations error, and is orthogonal to the interest rate differential, $i_{t, k}-i_{t, k}^{*}$. (Under the alternative, $\zeta_{t+k}$ could be an error term that does not fulfill the rational expectations criteria, and/or a time varying risk premium, possibly correlated with the interest differential.) In the regressions reported in this paper, the exact formulas are used instead of the log approximations.

Note that the intercept $\alpha$ may be non zero while testing for UIP using equation (4). A non zero may reflect a constant risk premium (hence, we are really testing for a time-varying risk premium, rather than risk neutrality per se) and/or approximation errors stemming from Jensens Inequality from the fact that expectation of a ratio (the exchange rate) is not equal to the ratio of the expectation.

Most of the studies fall into the category employing the rational expectations hypothesis; in our lexicon, that means they are tests of the unbiasedness hypothesis. Estimates of equation (4) using values for $\mathrm{k}$ that range up to one year typically reject the unbiasedness restriction on the slope parameter. The widely cited 1990 survey by Froot and Thaler finds an average estimate for $\beta$ of $-0.88^{1}$. Bansal and Dahlquist (2000) provide more mixed results, when examining a broader set of advanced and emerging market currencies. They also note that the failure of unbiasedness appears to depend upon whether the US interest rate is above or below the foreign ${ }^{2}$. Frankel and Poonawala

\footnotetext{
${ }^{1}$ Similar results are cited in surveys by MacDonald and Taylor (1992) and Isard (1995). Meese and Rogoff (1983) show that the forward rate is outpredicted by a random walk, which is consistent with the failure of the unbiasedness hypothesis.

${ }^{2}$ Flood and Rose $(1996,2002)$ note that including currency crises and devaluations, one finds more evidence for the unbiasedness hypothesis.
} 
(2010) show that for emerging markets more generally, the unbiasedness hypothesis coefficient is typically more positive ${ }^{3}$.

The earliest studies that explored the UIP hypothesis over long horizons include Flood and Taylor (1997) and Alexius (2001). Flood and Taylor (1997) explores the UIP relationship at three year horizon pooling 21 currencies of mostly developed countries, with the U.S. Dollar as the base currency. They estimate $\beta$ to be 0.596 with a standard error of 0.195 . However, the bond yields used are heterogeneous, with varying maturities, so are difficult to interpret. Alexius (2001) finds evidence of UIP holding at long horizon using 14 long term bonds of varying maturities, using a sample from 1957-97. As the sample encompasses the Bretton Woods era and the associated capital control regime, those findings are perhaps not applicable in current times.

Chinn and Meredith (2004) tested the UIP hypothesis at five year and ten year horizons for the Group of Seven (G7) countries, and found greater support for the unbiasedness hypothesis holding at these long horizons than in shorter horizons of three to twelve months. The estimated coefficient on the interest rate differentials were positive and were closer to the value of unity than to zero in general. The sample used in that paper extended up to 2000. Figure 1 depicts the indicated pattern - negative coefficients at short horizons, and positive coefficients at longer horizons, updated to 2007Q4, so as to exclude the effects of the global financial crisis and ensuing period of near zero interest rates.

[Figure 1 about here.]

In a sample extending up to 2011, Chinn and Quayyum (2013) find that the relationship between exchange rate changes and interest differentials has altered noticeably both at short and long horizons; the coefficients of different maturities for major currencies have declined in the wake of the Great Recession. This point is highlighted in Figure 2.

[Figure 2 about here.]

\section{The model}

In this section, we develop a standard small open-economy New Keynesian model following Galí (2008) and Walsh (2010).

The world economy constitutes of a continuum of small open economies represented by the unit interval $^{4}$. Since each economy is of measure zero, its performance does not have any impact on the

\footnotetext{
${ }^{3}$ There is an alternative approach that involves using survey-based data to measure exchange rate expectations. Chinn and Frankel (1994) document that it is difficult to reject UIP for a broad set of currencies when using survey based forecasts. Similar results are obtained by Chinn (2014), when extending the data up to 2009. These results echo early findings by Froot and Frankel (1989). While we do not pursue this avenue in this paper (long horizon expectations being difficult to obtain), it is useful to recall these findings when interpreting rejections of the joint hypothesis of UIP and rational expectations.

${ }^{4}$ In order to simplify the notation, variables without a $k$-index are used to refer to the small open economy being modeled. i.e., the Home country. Variables with a $k \in[0,1]$ subscript refer to economy $k$ other than the Home country, one among the continuum of economies making up the world economy. Finally, variables with an asterisk superscript * correspond to the world economy as a whole.
} 
rest of the world. In addition, we assume symmetry, that is, all countries share the same preference and technology $y^{5}$.

\subsection{Households}

Consumption preferences in the Home economy are described by the following composite index of domestic and imported bundles of goods:

$$
C_{t} \equiv\left[(1-\gamma)^{\frac{1}{a}}\left(C_{t}^{h}\right)^{\frac{a-1}{a}}+\gamma^{\frac{1}{a}}\left(C_{t}^{f}\right)^{\frac{a-1}{a}}\right]^{\frac{a}{a-1}}
$$

where $a>1$ is the elasticity of substitution between domestically produced and imported goods. $C_{t}^{h}$ (and $C_{t}^{f}$ ) are Dixit-Stiglitz aggregates of domestically produced and imported goods.

$$
C_{t}^{h} \equiv\left[\int_{0}^{1} C_{t}^{h}(j)^{\frac{\theta-1}{\theta}} d j\right]^{\frac{\theta}{\theta-1}}
$$

where $j \in[0,1]$ denotes the good variety. $C_{t}^{f}$ is an index of imported goods given by

$$
C_{t}^{f} \equiv\left[\int_{0}^{1}\left(C_{k, t}\right)^{\frac{\xi-1}{\xi}} d k\right]^{\frac{\xi}{\xi-1}}
$$

where $C_{k, t}$ is, in turn, an index of the quantity of goods imported from country $k$ and consumed by domestic households. It is given by an analogous CES function

$$
C_{k, t} \equiv\left[\int_{0}^{1} C_{k, t}(j)^{\frac{\theta-1}{\theta}} d j\right]^{\frac{\theta}{\theta-1}}
$$

The optimal allocation of any given expenditure within each category of goods yields the demand functions

$$
\begin{gathered}
C_{t}^{h}(j)=\left[\frac{P_{t}^{h}(j)}{P_{t}^{h}}\right]^{-\theta} C_{t}^{h} \\
C_{k, t}(j)=\left[\frac{P_{k, t}(j)}{P_{k, t}}\right]^{-\theta} C_{k, t}
\end{gathered}
$$

for all $j, k \in[0,1]$, where $P_{t}^{h}$ is the Home price index (i.e., the index of prices of domestically produced goods) defined as

$$
P_{t}^{h} \equiv\left[\int_{0}^{1} P_{t}^{h}(j)^{1-\theta} d j\right]^{\frac{1}{1-\theta}}
$$

and $P_{k, t}$ is a price index for goods imported from country $k$ (expressed in Home currency) for all $k \in[0,1]$

$$
P_{k, t} \equiv\left[\int_{0}^{1} P_{k, t}(j)^{1-\theta} d j\right]^{\frac{1}{1-\theta}}
$$

\footnotetext{
${ }^{5}$ For conciseness, in this paper we only specify technology for the Home country.
} 
We derive the price index for imported goods (also expressed in Home currency)

$$
P_{t}^{f} \equiv\left[\int_{0}^{1} P_{k, t}^{1-\xi} d k\right]^{\frac{1}{1-\xi}}
$$

The Home households's relative demand for $C_{t}^{h}$ and $C_{t}^{f}$ depends on their relative prices $P_{t}^{h}$ and $P_{t}^{f}$. It is easy to derive:

$$
\begin{aligned}
C_{t}^{h} & =(1-\gamma)\left(\frac{P_{t}^{h}}{P_{t}^{c}}\right)^{-a} C_{t} \\
C_{t}^{f} & =\gamma\left(\frac{P_{t}^{f}}{P_{t}^{c}}\right)^{-a} C_{t}
\end{aligned}
$$

where $P_{t}^{c}$ is the composite consumer price index defined as

$$
P_{t}^{c} \equiv\left[(1-\gamma)\left(P_{t}^{h}\right)^{1-a}+\gamma\left(P_{t}^{f}\right)^{1-a}\right]^{\frac{1}{1-a}}
$$

Agent maximize the following expected discounted sum of utilities over possible paths of consumption and labor:

$$
E_{0}\left\{\sum_{t=0}^{\infty} \beta^{t} U\left(C_{t}, N_{t}\right)\right\}
$$

where the period utility is defined as

$$
U\left(C_{t}, N_{t}\right)=\frac{C_{t}^{1-\sigma}}{1-\sigma}-\frac{N_{t}^{1+\eta}}{1+\eta}
$$

By considering the optimal expenditure conditions (14) and (15), the sequence of budget constraints assumes the following form:

$$
C_{t}+B_{t}=\frac{P_{t}^{h}}{P_{t}^{c}} Y_{t}+B_{t-1} \frac{1+i_{t-1}}{1+\pi_{t}^{c}}+T_{t}
$$

where $B_{t}$ is the bond holdings of representative home household ${ }^{6}$, and $T_{t}$ is the lump-sum profit transfer from the firms.

The representative household chooses processes $\left\{C_{t}, N_{t}\right\}_{t=0}^{\infty}$ and asset portfolio to maximize (17) subject to (19). For any given state of the world, the following set of efficiency conditions must hold:

$$
\begin{aligned}
C_{t}^{-\sigma} & =\beta E_{t}\left[\left(1+i_{t}\right)\left(\frac{P_{t}^{c}}{P_{t+1}^{c}}\right) C_{t+1}^{-\sigma}\right] \\
\frac{N_{t}^{\eta}}{C_{t}^{-\sigma}} & =\frac{W_{t}}{P_{t}^{c}}
\end{aligned}
$$

Equation (20) takes the form of a familiar consumption Euler equation. Notice that following large part of the recent literature, we do not introduce money explicitly.

\footnotetext{
${ }^{6}$ Since our model has a complete asset market (see Section 3.5), this budget constraint is an abbreviated version. We only use (19) to derive the IS curve. In fact, the household is subject to a complete set of assets against all sorts of risks.
} 


\section{$3.2 \quad$ Production and Price Setting}

A typical firm $j$ in the Home economy produces a differentiated good with a linear technology represented by the production function

$$
Y_{t}(j)=e^{\epsilon t} N_{t}(j)
$$

Let $Y_{t} \equiv\left[\int_{0}^{1} Y_{t}(j)^{\frac{\theta-1}{\theta}} d j\right]^{\frac{\theta}{\theta-1}}$ represent an index for aggregate domestic output, analogous to the introduced for consumption. Hence, notice that

$$
N_{t} \equiv \int_{0}^{1} N_{t}(j) d j=\frac{Y_{t} Z_{t}}{e^{\epsilon t}}
$$

where $Z_{t} \equiv \int_{0}^{1} \frac{Y_{t}(j)}{Y_{t}} d j$. Galí and Monacelli (2005) proved that equilibrium variations in $z_{t} \equiv \ln Z_{t}$ around the perfect foresight steady state are of second order. Thus, up to a first order approximation, we have an aggregate relationship

$$
y_{t}=n_{t}+\epsilon_{t}
$$

Each firm faces a constant elasticity demand curve for its output, The firm's real marginal cost is equal to

$$
M C_{t}=\frac{W_{t} / P_{t}^{h}}{e^{\epsilon t}}
$$

where $\frac{W_{t}}{P_{t}^{h}}$ is the real product wage and $e^{\epsilon_{t}}$ is the marginal product of labor. In terms of percentage deviations around the steady state, this expression becomes

$$
m c_{t}=w_{t}-p_{t}^{h}-\epsilon_{t}
$$

We assume that firms set prices in a staggered fashion, as in Calvo (1983). Hence, a measure $1-\omega$ of (randomly selected) firms sets new prices each period, with an individual firm's probability of re-optimizing in any given period being independent of the time elapsed since it last reset its price.

\subsection{The Law of One Price, Terms of Trade, and the Real Exchange Rate}

For the rest of the world, the distinction between the CPI and the price of domestic production is ignored, both denoted as $P_{t}^{*}$. That is, the rest of the world is large relative to the home country ${ }^{7}$, so changes in the price of home-produced goods have little impact on the consumer price index for the rest of the world. Because of asymmetry, all imported goods sell for the same price $P_{t}^{f}$ at home country. That is, $P_{k, t}(j)=P_{k, t}=P_{t}^{f}$ for any $j, k \in[0,1]$. Assume that the law of one price holds. This implies

$$
P_{t}^{f}=S_{t} P_{t}^{*}
$$

The terms of trade is the relative price of imported goods:

$$
\Delta_{t} \equiv \frac{P_{t}^{f}}{P_{t}^{h}}=\frac{S_{t} P_{t}^{*}}{P_{t}^{h}}
$$

\footnotetext{
${ }^{7}$ The home country is of measure zero.
} 
while the real exchange rate is defined as

$$
Q_{t}=\frac{S_{t} P_{t}^{*}}{P_{t}^{c}}=\left(\frac{P_{t}^{h}}{P_{t}^{c}}\right) \Delta_{t}
$$

With these new definitions, we can log-linearize (14), (15), (16), (20), and (21), and get (lowercase letters denote percentage deviation around the steady states of the corresponding uppercase letters)

$$
\begin{aligned}
c_{t}^{f} & =-a \delta_{t}+c_{t}^{h} \\
p_{t}^{c} & =(1-\gamma) p_{t}^{h}+\gamma p_{t}^{f}=p_{t}^{h}+\gamma \delta_{t} \\
c_{t} & =E_{t} c_{t+1}-\frac{1}{\sigma}\left(i_{t}-E_{t} \pi_{t+1}^{c}\right) \\
\eta n_{t}+\sigma c_{t} & =w_{t}-p_{t}^{h}-\gamma \delta_{t}
\end{aligned}
$$

where $\pi_{t}^{c}=p_{t}^{c}-p_{t-1}^{c}$. Defining inflation in the prices of domestically produced goods as $\pi_{t}^{h}=p_{t}^{h}-p_{t-1}^{h}$, inflation in the consumer price index equals

$$
\begin{aligned}
\pi_{t}^{c} & =p_{t}^{c}-p_{t-1}^{c} \\
& =\left(p_{t}^{h}+\gamma \delta_{t}\right)-\left(p_{t-1}^{h}+\gamma \delta_{t-1}\right) \\
& =\pi_{t}^{h}+\gamma\left(\delta_{t}-\delta_{t-1}\right)
\end{aligned}
$$

\subsection{The Rest of the World}

Since the home country is of zero measure, variables of the rest of the world is actually equivalent to the whole world. This means that it is unnecessary to distinguish between domestic output and consumption for the rest of the world. i.e. $C_{t}^{*}=Y_{t}^{*}$. Similar to (15), it is easy to derive

$$
C_{t}^{h *}=\gamma \Delta_{t}^{a} Y_{t}^{*}
$$

or

$$
c_{t}^{h *}=a \delta_{t}+y_{t}^{*}
$$

\subsection{Complete Asset Markets and International Risk Sharing}

We assume complete asset markets in this model. As we mentioned in Section 3.1, the household is subject to a complete set of assets against all sorts of risks. For any state $s$ of the economy at Period $\mathrm{t}+1$, there exists a corresponding Arrow security with price $v_{t}$ that pays one unit of Home currency in period $\mathrm{t}+1$ if and only if state $s$ occurs $^{8}$.

Assume state $s$ occurs with probability $\tau(s)$. Then for the Home households, intertemporal substitution yields:

$$
\frac{v_{t} U^{\prime}\left(C_{t}\right)}{P_{t}^{c}}=\frac{\beta U^{\prime}\left(C_{t+1}(s)\right) \tau(s)}{P_{t+1}^{c}(s)}
$$

\footnotetext{
${ }^{8}$ If such an Arrow security does not exist, we can always construct an identical portfolio from existing assets. This is guaranteed by the definition of complete asset markets.
} 
where $s$ in the parentheses means it is state dependent.

Substituting $U(\cdot)$ with its functional form, and a little tranformation, we can get

$$
\beta\left[\frac{C_{t+1}(s)^{-\sigma}}{C_{t}^{-\sigma}} \cdot \frac{P_{t}^{c}}{P_{t+1}^{c}(s)}\right]=\frac{v_{t}}{\tau(s)}
$$

The foreign households also have access to this Arrow security, and their intertemporal substitution yields:

$$
\frac{v_{t} U^{\prime}\left(C_{t}^{*}\right)}{S_{t} P_{t}^{*}}=\frac{\beta U^{\prime}\left(C_{t+1}^{*}(s)\right) \tau(s)}{S_{t+1}(s) P_{t+1}^{*}(s)}
$$

That is,

$$
\beta\left[\frac{C_{t+1}^{*}(s)^{-\sigma}}{C_{t}^{*-\sigma}} \cdot \frac{S_{t} P_{t}^{*}}{S_{t+1}(s) P_{t+1}^{*}(s)}\right]=\frac{v_{t}}{\tau(s)}
$$

i.e.,

$$
\beta\left[\frac{C_{t+1}^{*}(s)^{-\sigma}}{C_{t}^{*-\sigma}} \cdot \frac{Q_{t}}{Q_{t+1}(s)} \cdot \frac{P_{t}^{c}}{P_{t+1}^{c}(s)}\right]=\frac{v_{t}}{\tau(s)}
$$

Comparing (34) and (37), we can get

$$
\frac{C_{t+1}(s)^{-\sigma}}{C_{t}^{-\sigma}}=\frac{C_{t+1}^{*}(s)^{-\sigma}}{C_{t}^{*-\sigma}} \cdot \frac{Q_{t}}{Q_{t+1}(s)}
$$

i.e.,

$$
\frac{C_{t+1}(s)^{-\sigma}}{C_{t+1}^{*}(s)^{-\sigma}} Q_{t+1}(s)=\frac{C_{t}^{-\sigma}}{C_{t}^{*-\sigma}} Q_{t}
$$

The right hand side of the above equation is independent of state $s$, hence for any state $s$, we must have

$$
\frac{C_{t+1}^{-\sigma}}{C_{t+1}^{*-\sigma}} Q_{t+1}=\frac{C_{t}^{-\sigma}}{C_{t}^{*-\sigma}} Q_{t}
$$

This equation indicates $\frac{C_{t}^{-\sigma}}{C_{t}^{*-\sigma}} Q_{t}$ is a constant for any $t$. For convenience, normalize this constant to be unity. This is consistent with a symmetric initial condition with zero net foreign asset holdings. Hence we get

$$
C_{t}=Q_{t}^{\frac{1}{\sigma}} C_{t}^{*}
$$

and its log-linearized version

$$
c_{t}=c_{t}^{*}+\left(\frac{1}{\sigma}\right) q_{t}=c_{t}^{*}+\left(\frac{1-\gamma}{\sigma}\right) \delta_{t}
$$

The last equation employs the fact that

$$
\begin{aligned}
q_{t} & =s_{t}+p_{t}^{*}-p_{t}^{c} \\
& =\left(s_{t}+p_{t}^{*}-p_{t}^{h}\right)+\left(p_{t}^{h}-p_{t}^{c}\right) \\
& =\delta_{t}+\left(p_{t}^{h}-p_{t}^{c}\right) \\
& =\delta_{t}-\gamma \delta_{t} \\
& =(1-\gamma) \delta_{t}
\end{aligned}
$$




\subsection{Uncovered Interest Parity}

We model the uncovered interest parity equation following McCallum (1994) and Engel (2015), that the market's expectation of the currency depreciation differs from the rational expectation by a mean-zero, i.i.d. random variable $u_{i}$ :

$$
i_{t}-i_{t}^{*}=E_{t} s_{t+1}-s_{t}+u_{i t}
$$

The presence of this error term is crucial, and yet at the same time intuitively plausible. Perhaps agents in the market do not make the effort to calculate the fully rational expectations (such as in bounded rationality), so that each period they make an error in expectations formation that has a mean of zero and is completely transitory. Hence, the consequent deviation from rational expectations is not systematic. Evidence that market expectations are not unbiased comes from a variety of sources, including Chinn and Frankel (1994) and Chinn (2006), for instance.

Using the definition of real exchange rate, we re-write the interest parity equation

$$
i_{t}-i_{t}^{*}=E_{t} q_{t+1}-q_{t}+E_{t} \pi_{t+1}^{c}-E_{t} \pi_{t+1}^{*}+u_{i t}
$$

\subsection{Market Clearing Condition}

Market clear requires that Home production equal the consumption of the Home produced good. Since the Home produced good is consumed by both Home residents and by residents of the rest of the world, equilibrium requires

$$
Y_{t}=(1-\gamma)\left(\frac{P_{t}^{h}}{P_{t}^{c}}\right)^{-a} C_{t}+\gamma\left(\frac{P_{t}^{h}}{S_{t} P_{t}^{*}}\right)^{-a} Y_{t}^{*}
$$

Using (41) $C_{t}=Q_{t}^{\frac{1}{\sigma}} C_{t}^{*}=Q_{t}^{\frac{1}{\sigma}} Y_{t}^{*}$ to eliminate $Y_{t}^{*}$, and employing the definition of the real exchange rate, the good market equilibrium condition can be written as

$$
Y_{t}=\left(\frac{P_{t}^{h}}{P_{t}^{c}}\right)^{-a}\left[(1-\gamma)+\gamma Q_{t}^{\left(a-\frac{1}{\sigma}\right)}\right] C_{t}
$$

Log-linearize this equation yields:

$$
\begin{aligned}
y_{t} & =-a\left(p_{t}^{h}-p_{t}^{c}\right)+\gamma\left(a-\frac{1}{\sigma}\right) q_{t}+c_{t} \\
& =\gamma a \delta_{t}+\gamma\left(a-\frac{1}{\sigma}\right) q_{t}+c_{t} \\
& =\frac{\gamma a}{1-\gamma} q_{t}+\gamma\left(a-\frac{1}{\sigma}\right) q_{t}+c_{t} \\
& =c_{t}+\frac{\gamma}{\sigma(1-\gamma)}[a \sigma+(a \sigma-1)(1-\gamma)] q_{t} \\
& =c_{t}^{*}+\frac{1}{\sigma} q_{t}+\frac{\gamma}{\sigma(1-\gamma)}[a \sigma+(a \sigma-1)(1-\gamma)] q_{t} \\
& =y_{t}^{*}+\frac{1}{\sigma} q_{t}+\frac{\gamma}{\sigma(1-\gamma)}[a \sigma+(a \sigma-1)(1-\gamma)] q_{t} \\
& =y_{t}^{*}+\frac{1}{\sigma_{\gamma}(1-\gamma)} q_{t}
\end{aligned}
$$


where $\sigma_{\gamma} \equiv \frac{\sigma}{1-\gamma(1-a \sigma)(2-\gamma)}$

\subsection{Inflation Adjustment and the Phillips Curve}

In the small open economy, the dynamics of domestic inflation in terms of real marginal cost are described by an equation analogous to the one associated with a closed economy ${ }^{9}$. Hence,

$$
\pi_{t}^{h}=\beta E_{t} \pi_{t+1}^{h}+k \cdot m c_{t}
$$

where $k \equiv \frac{(1-\omega)(1-\beta \omega)}{\omega}$. From $(23),(30),(48)$, and $(49)$, we have

$$
\begin{aligned}
m c_{t} & =w_{t}-p_{t}^{h}-\epsilon_{t} \\
& =\eta n_{t}+\sigma c_{t}+\gamma \delta_{t}-\epsilon_{t} \\
& =\eta\left(y_{t}-\epsilon_{t}\right)+\sigma c_{t}+\gamma \delta_{t}-\epsilon_{t} \\
& =\eta y_{t}+\sigma c_{t}+\frac{\gamma}{1-\gamma} q_{t}-(1+\eta) \epsilon_{t} \\
& =\eta y_{t}+\sigma\left\{y_{t}-\frac{\gamma}{\sigma(1-\gamma)}[a \sigma+(a \sigma-1)(1-\gamma)] q_{t}\right\}+\frac{\gamma}{1-\gamma} q_{t}-(1+\eta) \epsilon_{t} \\
& =(\eta+\sigma) y_{t}+\frac{\sigma_{\gamma}-\sigma}{\sigma_{\gamma}(1-\gamma)} q_{t}-(1+\eta) \epsilon_{t} \\
& =(\eta+\sigma) y_{t}+\left(\sigma_{\gamma}-\sigma\right)\left(y_{t}-y_{t}^{*}\right)-(1+\eta) \epsilon_{t} \\
& =\left(\eta+\sigma_{\gamma}\right) y_{t}+\left(\sigma-\sigma_{\gamma}\right) y_{t}^{*}-(1+\eta) \epsilon_{t}
\end{aligned}
$$

Thus (50) can be re-written as:

$$
\pi_{t}^{h}=\beta E_{t} \pi_{t+1}^{h}+k\left[\left(\eta+\sigma_{\gamma}\right) y_{t}+\left(\sigma-\sigma_{\gamma}\right) y_{t}^{*}\right]+u_{c t}
$$

where $u_{c t} \equiv-k(1+\eta) \epsilon_{t}$ is defined as the cost/productivity shock. A positive $u_{c t}$ indicates a decrease in Home productivity.

\subsection{Monetary Policy Rule for the Small Open Economy}

Assume Home monetary authority adopts a stylized Taylor-type rule, where the domestic interest rate respond systematically to (expected) domestic inflation, output, and expected real exchange rate depreciation:

$$
\begin{aligned}
i_{t} & =\delta_{\pi} E_{t} \pi_{t+1}^{c}+\delta_{y} y_{t}+u_{m t} \\
& =\delta_{\pi} E_{t} \pi_{t+1}^{h}+\delta_{y} y_{t}+\frac{\delta_{\pi} \gamma}{1-\gamma} E_{t} \Delta q_{t+1}+u_{m t}
\end{aligned}
$$

where $u_{m t}$ is an exogenous shock to the monetary policy. The second equation follows from (31).

\footnotetext{
${ }^{9}$ See Galí and Monacelli (2005) for derivation.
} 


\subsection{Term Structure of Interest Rates}

Intertemporal substitution between an N-period maturity bond (with interest rate denoted by $i_{t}^{l}(N)$ ) and a one-period maturity bond requires

$$
\begin{aligned}
\frac{U^{\prime}\left(C_{t}\right)}{P_{t}} & =E_{t}\left[\frac{\beta^{N} U^{\prime}\left(C_{t+N}\right)\left(1+i_{t}^{l}(N)\right)^{N}}{P_{t+N}}\right] \\
\frac{U^{\prime}\left(C_{t}\right)}{P_{t}} & =E_{t}\left[\frac{\beta^{N} U^{\prime}\left(C_{t+N}\right) \prod_{j=0}^{N-1}\left(1+i_{t+j}\right)}{P_{t+N}}\right]
\end{aligned}
$$

Consequently, we have

$$
E_{t}\left[\frac{C_{t+N}^{-\sigma}\left(1+i_{t}^{l}(N)\right)^{N}}{P_{t+N}}\right]=E_{t}\left[\frac{C_{t+N}^{-\sigma} \prod_{j=0}^{N-1}\left(1+i_{t+j}\right)}{P_{t+N}}\right]
$$

Log-linearization of the above equation leads to the expectation hypothesis of the term structure (EHTS)

$$
i_{t}^{l}(N)=\frac{\sum_{j=0}^{N-1} E_{t} i_{t+j}}{N}
$$

That is, the long-term interest rate is determined as the average of the current short-term interest rate and its expected value over the subsequent periods.

There is an important asymmetry in our treatment of the households maximization problem with respect to the intertemporal dimension versus the cross-country dimension; in the latter we have appended a disturbance term, while none such exists in the EHTS just described. This implicit segmentation is consistent with the evidence provided by Alexius and Sellin (2006), showing that parity between yields on short term instruments fails to hold while parity cannot be rejected on holding period returns on long term instruments.

\subsection{Model Summary}

The model is summarized by the following dynamic system:

- Interest Parity (From (45))

$$
i_{t}-i_{t}^{*}=E_{t} q_{t+1}-q_{t}+E_{t} \pi_{t+1}^{c}-E_{t} \pi_{t+1}^{*}+u_{i t}
$$

- Phillips Curve (From (52))

$$
\pi_{t}^{h}=\beta E_{t} \pi_{t+1}^{h}+k\left[\left(\eta+\sigma_{\gamma}\right) y_{t}+\left(\sigma-\sigma_{\gamma}\right) y_{t}^{*}\right]+u_{c t}
$$

- Market Clear (From (49))

$$
y_{t}=y_{t}^{*}+\frac{1}{\sigma_{\gamma}(1-\gamma)} q_{t}
$$


- Taylor Rule (From (53))

$$
i_{t}=\delta_{\pi} E_{t} \pi_{t+1}^{h}+\delta_{y} y_{t}+\frac{\delta_{\pi} \gamma}{1-\gamma} E_{t} \Delta q_{t+1}+u_{m t}
$$

- Relationship between $\pi_{t}^{c}$ and $\pi_{t}^{h}$ (From (31) and (43))

$$
\pi_{t}^{c}=\pi_{t}^{h}+\frac{\gamma}{1-\gamma}\left(q_{t}-q_{t-1}\right)
$$

- Term Structure of Interest Rates (From (57))

$$
i_{t}^{l}(N)=\frac{\sum_{j=0}^{N-1} E_{t} i_{t+j}}{N}
$$

- Nominal Exchange Rate Depreciation (From (44))

$$
E_{t} s_{t+1}-s_{t}=i_{t}-i_{t}^{*}-u_{i t}
$$

The intertemporal substitution equation (20) is implied by international risk sharing (42), market clear condition (60) and term structure of interest rates (63), so we do not include it here.

\section{Model Calibration}

In this section, we calibrate the model and show that the calibrated New Keynesian model captures the pre-ZLB (1975Q1-1995Q4) volatility of Japanese 3-month T-bill rate and depreciation of nominal exchange rate (with U.S. dollar as the base currency). We focus on interest rate and depreciation of nominal exchange rate because this paper is about whether interest rate ZLB would affect the coefficient of Fama regression ${ }^{10}$.

\subsection{Empirical Moments}

The Japanese data come from the IMF's International Financial Statistics (IFS) database. We use quarterly observations on Japanese 3-month T-bill rate and depreciation of (log) nominal exchange rate, starting from 1975Q1 to 1995Q4. The motivation for choosing such sample period is that it starts from the flexible exchange rate regime, and ends before the advent of the ZLB interest rate regime $^{11}$. We also use U.S. 3-month T-bill rate from Federal Reserve Board's H.15 release as the world interest rate. The variance and $90 \%$ confidence intervals are summarized as follows ${ }^{12}$ :

[Table 1 about here.]

\footnotetext{
${ }^{10}$ We can also match the moments for other macroeconomic variables, e.g., output by imposing habit persistence structure. We do not impose such structure because it brings unnecessary complication without helping us understand the nature of ZLB.

${ }^{11}$ Following Chinn and Meredith (2004), Chinn and Quayyum (2013).

${ }^{12}$ Both the depreciation rate and the interest rate are expressed at annual rate, i.e., percent per annum.
} 


\subsection{Theoretical Predictions}

We impose the following additional assumptions:

1. There is no structure change during the period under consideration (1975Q1-1995Q4).

2. Without loss of generality, foreign/world economic variables (output, interest rate, etc.) are assumed to be constant.

3. All shocks are assumed to be either white noise or stationary $\operatorname{AR}(1)$ process:

$$
\begin{aligned}
u_{i t} & =\rho_{i} u_{i t-1}+e_{i t} \\
u_{c t} & =\rho_{c} u_{c t-1}+e_{c t} \\
u_{m t} & =\rho_{m} u_{m t-1}+e_{m t}
\end{aligned}
$$

where $\rho_{i}=0$. That is, the interest parity shock $u_{i t}$ is an i.i.d white noise, which is consistent with our assumption in Section 3.6.

In our open-economy New Keynesian model, one period is defined as one quarter. We calibrate and summarize the parameter values in Table $2^{13}$. The parameter values are standard and mostly follow Sanchez (2005), and Braun and Körber (2011). For instance, we set Calvo-pricing parameter $\omega=0.89$, indicating that Japanese firms reset prices every 9 quarters, which is consistent with Sanchez (2005)'s estimation that Japan's $\omega$ varies from 0.58 to 0.92 .

[Table 2 about here.]

The variances of the exchange rate depreciation and interest differential implied by the theoretical model are 0.004544 and 0.000688 respectively, which lie within the $90 \%$ confidence interval derived from the actual data (Table 1), and are quite close to the variance estimated from the actual data.

\section{Uncovered Interest Parity far from the ZLB}

\subsection{Closed-Form Solution}

Given the VAR system summarized in Section 3.11 and 4.2, our model has a closed-form solution that $i_{t}-i_{t}^{*}, E_{t} s_{t+1}-s_{t}, q_{t}, \pi_{t}^{h}$, etc, are linear combinations of the $\operatorname{AR}(1)$ shocks $u_{i t}, u_{c t}$, and $u_{m t}$. Without loss of generality, we shall write the solution as:

$$
\begin{aligned}
i_{t}-i_{t}^{*} & =c_{1} u_{i t}+c_{2} u_{c t}+c_{3} u_{m t} \\
E_{t} s_{t+1}-s_{t} & =-\left(1-c_{1}\right) u_{i t}+c_{2} u_{c t}+c_{3} u_{m t}
\end{aligned}
$$

[Figure 3 about here.]

\footnotetext{
${ }^{13}$ Because of symmetry, $\theta$ and $\xi$ do not enter the VAR system in Section 3.11. Hence we do not specify their values in Table 2. We will discuss $\bar{i}$ in Section 6 , when the interest rate is near ZLB.
} 
[Figure 4 about here.]

[Figure 5 about here.]

To illustrate the model's properties, Figure 3 - 5 shows impulse responses for one standard deviation innovations in $u_{i t}\left(e_{i t}\right)$ for the nominal exchange rate depreciation, and interest rates over different horizons ${ }^{1415}$. Our simulation indicates $c_{1}=0.2^{16}$.

[Figure 6 about here.]

[Figure 7 about here.]

[Figure 8 about here.]

[Figure 9 about here.]

[Figure 10 about here.]

[Figure 11 about here.]

Figure 6 - 11 shows impulse responses for standardized innovations in $u_{c t}\left(e_{c t}\right)$ and $u_{m t}\left(e_{m t}\right)$ for the nominal exchange rate depreciation over different horizons, and interest rates with different maturities. All the impulse response functions are intuitive. A positive cost shock $e_{c t}$ indicates a decrease in Home productivity. Home output decreases and inflation increases - this is the wellknown phenomenon of stagflation. After trade-off between inflation and unemployment, the central bank will set a higher interest rate to eliminate inflation. This also brings an expected depreciation of Home currency. A positive monetary shock $e_{m t}$ has a similar effect. It implies the central bank increases interest rate unexpectedly. Obviously it increases interest rate and expected depreciation instantly. Our simulation indicates $c_{2}=1.95$ and $c_{3}=-0.0655^{17}$. The closed-form solution also provides a convenient way to calculate the theoretical moments ${ }^{18}$.

\footnotetext{
${ }^{14}$ In those graphs, i_2 refers to interest rate with 6-month (2-quarter) maturity. ds_2 refers to depreciation rate over two quarters. Similar definitions apply for other variables.

${ }^{15}$ For conciseness, we do not include IRFs for all horizons.

${ }^{16}$ From Figure 3, it is straightforward to see $\frac{\partial\left(i_{t}-i_{t}^{*}\right)}{\partial e_{i t}} \operatorname{std}\left(e_{i t}\right)=0.004$. Since $\operatorname{std}\left(e_{i t}\right)=0.02$, it is straightforward to see $c_{1}=\frac{\partial\left(i_{t}-i_{t}^{*}\right)}{\partial e_{i t}}=0.2$.

${ }^{17}$ Figure 6 and Figure 9 show $\frac{\partial\left(i_{t}-i_{t}^{*}\right)}{\partial e_{c t}} \operatorname{std}\left(e_{c t}\right)=0.0039$ and $\frac{\partial\left(i_{t}-i_{t}^{*}\right)}{\partial e_{m} t} \operatorname{std}\left(e_{m t}\right)=-0.000131826$. Since $s t d\left(e_{c t}\right)=$ $\operatorname{std}\left(e_{m t}\right)=0.002$, we have $c_{2}=\frac{\partial\left(i_{t}-i_{t}^{*}\right)}{\partial e_{c t}}=1.95$ and $c_{3}=\frac{\partial\left(i_{t}-i_{t}^{*}\right)}{\partial e_{m t}}=-0.0655$.

${ }^{18}$ Note in our simulation, the depreciation rate and interest rate are quarterly rate, i.e., percent per quarter. Hence, variances derived from equations (65) and (66) should be multiplied by 16 to compare with the empirical moments in Table 1.
} 


\subsection{The Fama Coefficient at the Short Horizon}

Recall that $u_{i t}\left(e_{i t}\right)$ is a deviation from rational expectation, econometric theory suggests the coefficient of Fama regression satisfy:

$$
\begin{aligned}
\operatorname{plim} \hat{\beta} & =\frac{\operatorname{cov}\left(s_{t+1}-s_{t}, i_{t}-i_{t}^{*}\right)}{\operatorname{var}\left(i_{t}-i_{t}^{*}\right)} \\
& =\frac{\operatorname{cov}\left(E_{t} s_{t+1}-s_{t}, i_{t}-i_{t}^{*}\right)}{\operatorname{var}\left(i_{t}-i_{t}^{*}\right)} \\
& =\frac{\operatorname{cov}\left(i_{t}-i_{t}^{*}-u_{i t}, i_{t}-i_{t}^{*}\right)}{\operatorname{var}\left(i_{t}-i_{t}^{*}\right)} \\
& =\frac{\operatorname{var}\left(i_{t}-i_{t}^{*}\right)-\operatorname{cov}\left(u_{i t}, i_{t}-i_{t}^{*}\right)}{\operatorname{var}\left(i_{t}-i_{t}^{*}\right)} \\
& =1-\frac{\operatorname{cov}\left(u_{i t}, i_{t}-i_{t}^{*}\right)}{\operatorname{var}\left(i_{t}-i_{t}^{*}\right)} \\
& =1-\frac{\operatorname{cov}\left(u_{i t}, c_{1} u_{i t}+c_{2} u_{c t}+c_{3} u_{m t}\right)}{\operatorname{var}\left(i_{t}-i_{t}^{*}\right)} \\
& =1-\frac{\operatorname{cov}\left(u_{i t}, c_{1} u_{i t}\right)}{\operatorname{var}\left(i_{t}-i_{t}^{*}\right)} \\
& =1-\frac{c_{1} \operatorname{var}\left(u_{i t}\right)}{\operatorname{var}\left(i_{t}-i_{t}^{*}\right)} \\
& =1-\frac{c_{1} \operatorname{var}\left(u_{i t}\right)}{c_{1}^{2} \operatorname{var}\left(u_{i t}\right)+c_{2}^{2} \operatorname{var}\left(u_{c t}\right)+c_{3}^{2} \operatorname{var}\left(u_{m t}\right)}
\end{aligned}
$$

According to our calibration, $u_{i t}\left(e_{i t}\right)$ is more volatile than $u_{c t}\left(e_{c t}\right)$ and $u_{m t}\left(e_{m t}\right)$. At short horizon, $u_{i t}\left(e_{i t}\right)$ dominates. Hence at short horizon Fama regression generally yields a negative coefficient. From our derivation (67), it is straightforward to see the endogeneity caused by $u_{i t}$ makes this estimator deviate from unity, and sometimes being negative.

\subsection{The Long Horizon}

In the long run, $\operatorname{plim} \hat{\beta}(N)^{19}$ becomes

$$
\begin{aligned}
\operatorname{plim} \hat{\beta}(N) & =\frac{\operatorname{cov}\left(\sum_{j=0}^{N-1}\left(s_{t+j+1}-s_{t+j}\right), \sum_{j=0}^{N-1} E_{t}\left(i_{t+j}-i_{t+j}^{*}\right)\right)}{\operatorname{var}\left(\sum_{j=0}^{N-1} E_{t}\left(i_{t+j}-i_{t+j}^{*}\right)\right)} \\
& =\frac{\operatorname{cov}\left(\sum_{j=0}^{N-1} E_{t}\left(s_{t+j+1}-s_{t+j}\right), \sum_{j=0}^{N-1} E_{t}\left(i_{t+j}-i_{t+j}^{*}\right)\right)}{\operatorname{var}\left(\sum_{j=0}^{N-1} E_{t}\left(i_{t+j}-i_{t+j}^{*}\right)\right)} \\
& =1-\frac{\operatorname{cov}\left(\sum_{j=0}^{N-1} E_{t} u_{i t+j}, \sum_{j=0}^{N-1} E_{t}\left(i_{t+j}-i_{t+j}^{*}\right)\right)}{\operatorname{var}\left(\sum_{j=0}^{N-1} E_{t}\left(i_{t+j}-i_{t+j}^{*}\right)\right)} \\
& =1-\frac{c_{1} \operatorname{var}\left(u_{i t}\right)}{c_{1}^{2} \operatorname{var}\left(u_{i t}\right)+c_{2}^{2} \operatorname{var}\left(\sum_{j=0}^{N-1} E_{t} u_{c t+j}\right)+c_{3}^{2} \operatorname{var}\left(\sum_{j=0}^{N-1} E_{t} u_{m t+j}\right)}
\end{aligned}
$$

\footnotetext{
${ }^{19} N$ is the horizon/maturity of the long term bond.
} 
At long horizon, since the cost shock $u_{c t}$ and monetary shock $u_{m t}$ are more persistent than $u_{i t}(\mathrm{AR}(1)$ v.s. white noise), as horizon increases, they tend to make greater contribution to $\operatorname{cov}\left(\sum_{j=0}^{N-1}\left(s_{t+j+1}-s_{t+j}\right), \sum_{j=0}^{N-1} E_{t}\left(i_{t+j}-i_{t+j}^{*}\right)\right)$. That is, in (68), $\operatorname{var}\left(\sum_{j=0}^{N-1} E_{t} u_{c t+j}\right)$ and $\operatorname{var}\left(\sum_{j=0}^{N-1} E_{t} u_{t+j}\right)$ increases as $N$ grows, so we would get a larger Fama regression coefficient estimate at longer horizon. Hence, we expect to find unbiasedness hypothesis holds better at long horizons than at short in our simulated data. Strictly, we have the following proposition:

Proposition 1 plim $\hat{\beta}(N)$ is monotonically increasing in $N$.

Proof. Straightforward.

\subsection{Simulation Results}

In this sub-section, stochastic simulations were performed on the model. Each simulation was performed over a 100 periods. This process was repeated 1000 times to generate a hypothetical population of 1000 such draws. For each draw, standard UIP regression were run, using horizons varying from 1 to 40 quarters. The average parameters as well as their confidence intervals are shown in Figure 12 .

[Figure 12 about here.]

The simulated results are consistent with our analysis in Section 5.2 and 5.3, as well as Chinn and Meredith (2004).

\section{Uncovered Interest Parity near the ZLB}

When the interest rate is near the ZLB, Taylor rule (61) has to be re-written as

$$
i_{t}=\max \left\{0, \delta_{\pi} E_{t} \pi_{t+1}^{h}+\delta_{y} y_{t}+\frac{\delta_{\pi} \gamma}{1-\gamma} E_{t} \Delta q_{t+1}+u_{m t}\right\}
$$

This brings about two important changes to the economy:

\section{(i) The Transmission Mechanism}

When the interest rate is positive, $u_{i t}$ and $u_{c t}$ affect central bank's monetary policy decisions and enter $i_{t}$ via $E_{t} \pi_{t+1}^{h}, y_{t}$ and $E_{t} \Delta q_{t+1}$, and $u_{m t}$ affects $i_{t}$ directly. Then the interest rate affects household intertemporal substitution decisions, and determines demand, which in turn, affects inflation, output and the exchange rate. However, if the ZLB is binding, such a transmission mechanism is shut down. When the shocks $u_{i t}, u_{c t}$, and $u_{m t}$ enter in the determination of $i_{t}$, $i_{t}$ will remain at zero, and these disturbances are blocked.

\section{(ii) Household Expectations and Intertemporal Substitution}


When the ZLB is binding, $i_{t}$ will remain at zero despite the realization of $u_{i t}, u_{c t}$, and $u_{m t}$. The households are able to anticipate this situation ahead of time, so they will adjust their intertemporal substitution decisions accordingly ${ }^{20}$.

With these changes, a closed-form solution no longer exists, and we cannot derive plim $\hat{\beta}$ as in Section 5.2 and 5.3. Nonetheless, in our model, both $s_{t+1}-s_{t}$ and $i_{t}-i_{t}^{*}$ (as well as $i_{t}$ ) are driven by three shocks $u_{i t}\left(e_{i t}\right), u_{c t}\left(e_{c t}\right)$, and $u_{m t}\left(e_{m t}\right)$, where $u_{i t}$ is volatile but transitory, and the other two disturbances are less volatile but more persistent.

$\bar{i}$ - the steady state level of $i_{t}^{21}$ plays an important role with occasionally binding ZLB. If $\bar{i}$ is large, then ZLB does not bind very often. When it does bind, it is most likely triggered by a negative $u_{i t}\left(e_{i t}\right)$, and the possibility of binding ZLB is generally random. This approach is denoted by "Random ZLB". However, if $\bar{i}$ is small, then ZLB binds more frequently. When it binds, it is often triggered by a negative $u_{c t}\left(e_{c t}\right)$ or $u_{m t}\left(e_{m t}\right)$, and the interest rate series are segmented. i.e., if $i_{t}=0$, then it is very likely that its adjacent leads and lags are also zero. If $i_{t}>0$, then it is very likely that its adjacent leads and lags are also positive. This is determined by the different degree of persistence and volatility of different shocks. This approach is denoted by "Persistent ZLB".

Again, we perform stochastic simulations for our model with ZLB constraint. Our simulation (with ZLB) method follows Holden and Paetz (2012), as well as Erceg and Lindé (2014). Each simulation was performed over a 100 periods. This process was repeated 1000 times to generate a hypothetical population of 1000 such draws. In our simulation, about half the time (49.99\%) the interest hits ZLB. Figure 13 is one such random draw of 100-period simulation, where the interest ZLB constraint follows "Persistent ZLB" approach. This indicates our simulation is consistent with the fact that Japan (starting from 1996) set their short term interest rate (close to) zero for several consecutive years.

[Figure 13 about here.]

With "Persistent ZLB", most binding ZLB periods are triggered by a negative $u_{c t}\left(e_{c t}\right)$ or $u_{m t}$ $\left(e_{m t}\right)$. That is, the shocks $u_{c t}\left(e_{c t}\right)$ and $u_{m t}\left(e_{m t}\right)$ are suppressed under ZLB constraints. Recall in Section 5.2, we showed volatility of $u_{c t}\left(e_{c t}\right)$ and $u_{m t}\left(e_{m t}\right)$ are critical to offset the endogeneity caused by $u_{i t}\left(e_{i t}\right)$. Once $u_{c t}\left(e_{c t}\right)$ and $u_{m t}\left(e_{m t}\right)$ are suppressed by ZLB constraints, the endogeneity problem deteriorates, hence we would expect the constrained Fama regression coefficient to be less positive. That is, unbiasedness hypothesis holds worse when interest rate is near ZLB. Such property is summarized in Figure 14, and it is consistent with Figure 2, and Chinn and Quayyum (2013).

[Figure 14 about here.]

\footnotetext{
${ }^{20} \mathrm{~A}$ common mistake is to write the solution as $i_{t}-i_{t}^{*}=\max \left\{0, c_{1} u_{i t}+c_{2} u_{c t}+c_{3} u_{m t}\right\}$ and $E_{t} s_{t+1}-s_{t}=i_{t}-i_{t}^{*}-u_{i t}$. This is wrong because it does not take into account the fact that the households are able to anticipate ZLB ahead of time. Actually, a closed-form solution does not exist when the interest rate is near ZLB.

${ }^{21}$ The so-defined $\bar{i}$ also includes other constants omitted by log-linearization. Hence it does not necessarily equal $\frac{1}{\beta}-1$. For conciseness, it is still referred to as "the steady state level of $i_{t}$ ".
} 


\section{Conclusion}

Two empirical findings underpin the exercises conducted in this paper. First, interest differentials at longer horizons tend to correlate positively with exchange rate depreciation, while those at short horizons tend to correlate negatively. Second, long horizon interest differentials tend to reject the unbiasedness hypothesis more strongly for exchange rates that involve a currency that has experienced low interest rates for an extended period. To the extent that low interest rates are likely to be a part of the global economic landscape for some time, it is of interest to know why this finding obtains.

Using a standard New Keynesian DSGE, incorporating sticky prices, we show how these empirical findings can be rationalized. The long horizon/short horizon dichotomy stylized fact is shown using a random (non-persistent) shock to the UIP relationship, along with persistent aggregate supply and monetary policy shocks. The attenuation in the long horizon unbiasedness in the era of low interest rates is replicated by simulating the NK DSGE in the presence of a zero lower bound.

\section{References}

[1] Alexius, A. (2001). "Uncovered Interest Parity Revisited," Review of International Economics, $9(3): 505-17$.

[2] Alexius, A. and P. Sellin (2006). "Exchange Rates and Long Term Bonds," mimeo (March).

[3] Bansal, R. and M. Dahlquist (2000). "The Forward Premium Puzzle: Different Tales from Developed and Emerging Economies," Journal of International Economics, 51: 115-144.

[4] Braun, R. A. and L. M. Körber (2011). "New Keynesian Dynamics in a Low Interest Rate Environment," Journal of Economic Dynamics \& Control, 35: 2213-2227.

[5] Calvo, G.A. (1983). "Staggered Prices in a Utility-Maximizing Framework," Journal of Monetary Economics, 12: 383-398.

[6] Chinn, M.D. (2006). "The (Partial) Rehabilitation of Interest Rate Parity: Longer Horizons, Alternative Expectations and Emerging Markets," Journal of International Money and Finance, 25(1) (February): 7-21.

[7] Chinn, M.D. (2014). "(Almost) A Quarter Century of Currency Expectations Data: Interest Rate Parity and the Risk Premium," mimeo (August).

[8] Chinn, M.D. and J.A. Frankel (1994). "Patterns in Exchange Rate Forecasts for 25 Currencies," Journal of Money, Credit and Banking, 26 (4) (November): 759-770.

[9] Chinn, M.D. and G. Meredith (2004). "Monetary Policy and Long-Horizon Uncovered Interest Parity," IMF Staff Papers, 51(3): 409-430.

[10] Chinn, M.D. and S. Quayyum (2013). "Long Horizon Uncovered Interest Parity Re-Assessed," mimeo. 
[11] Engel, C. (2015). "Exchange Rates and Interest Parity," in Handbook of International Economics, 4: 453-522, North Holland: Elsevier.

[12] Erceg, C. and J. Lindé (2014). "Is There a Fiscal Free Lunch in a Liquidity Trap?," Journal of the European Economic Association, 12(1): 73-107.

[13] Fama, E. (1984). "Forward and Spot Exchange Rate," Journal of Monetary Economics, 14: 319-38.

[14] Flood, R.P. and A.K. Rose (1996). "Fixes: Of the Forward Discount Puzzle," Review of Economics and Statistics, 748-752.

[15] Flood, R.P. and A.K. Rose (2002). "Uncovered Interest Parity in Crisis," IMF Staff Papers, 49: $252-66$.

[16] Flood, R.P. and M.P. Taylor (1997). "Exchange Rate Economics: Whats Wrong with the Conventional Macro Approach?" in The Microstructure of Foreign Exchange Markets, 262-301, Chicago: U.Chicago for NBER.

[17] Frankel, J.A. and J. Poonawala (2010). "The Forward Market in Emerging Currencies: Less Biased than in Major Currencies," Journal of International Money and Finance, 29(3): 585-598.

[18] Froot, K.A. and J.A. Frankel (1989). "Forward Discount Bias: Is It an Exchange Risk Premium?" Quarterly Journal of Economics,104(1) (February): 139-161.

[19] Froot, K.A. and R.H. Thaler (1990). "Foreign Exchange," Journal of Economic Perspectives, 4(3) (Summer): 179-192.

[20] Galí, J. (2008). "Monetary Policy, Inflation and the Business Cycle: An Introduction to the New Keynesian Framework," Princeton, NJ: Princeton University Press.

[21] Galí, J. and T. Monacelli (2005). "Monetary Policy and Exchange Rate Volatility in a Small Open Economy," Review of Economic Studies, 72: 707-734.

[22] Holden, T. and M. Paetz (2012). "Efficient Simulation of DSGE Models with Inequality Constraints," working paper.

[23] Isard, P. (1995). "Exchange Rate Economics," Cambridge: Cambridge University Press.

[24] Macdonald, R. and M.P. Taylor (1992). "Exchange Rate Economics: A Survey," IMF Staff Papers, 39(1): 1-57.

[25] McCallum, B.T. (1994). "A Reconsideration of the Uncovered Interest Parity Relationship," Journal of Monetary Economics, 33: 105-32.

[26] Meese, R. and K. Rogoff (1983). "Empirical Exchange Rate Models of the Seventies: Do They Fit Out of Sample?" Journal of International Economics, 14: 3-24.

[27] Sanchez, D. A. (2005). "Inflation Dynamics in Japan: The Calvo Model and Wage Rigidity," working paper.

[28] Walsh, C. E. (2010). "Monetary Theory and Policy," Cambridge: MA: MIT Press. 


\section{List of Figures}

1 Panel Fama coefficients 1980Q1-2007Q4, unbalanced, with fixed effects . . . . . . . . 22

2 Panel Fama coefficients . . . . . . . . . . . . . . . . . . . 23

3 The impulse response function of $e_{i t}$ on macroeconomic variables . . . . . . . . . 24

4 The impulse response function of $e_{i t}$ on macroeconomic variables . . . . . . . . 25

5 The impulse response function of $e_{i t}$ on macroeconomic variables $\ldots \ldots 26$

6 The impulse response function of $e_{c t}$ on macroeconomic variables . . . . . . . . 27

7 The impulse response function of $e_{c t}$ on macroeconomic variables . . . . . . . 28

8 The impulse response function of $e_{c t}$ on macroeconomic variables . . . . . . . . . 29

9 The impulse response function of $e_{m t}$ on macroeconomic variables $\ldots \ldots$

10 The impulse response function of $e_{m t}$ on macroeconomic variables $\ldots \ldots . \ldots 31$

11 The impulse response function of $e_{m t}$ on macroeconomic variables $\ldots \ldots . \ldots 32$

12 UIP slope parameter from model simulations . . . . . . . . . . . . . . . . . 33

13 A sample simulation of 100 periods with ZLB . . . . . . . . . . . . . . 34

14 Unconstrained v.s. constrained UIP slope parameters from model simulations . . . . . 35 


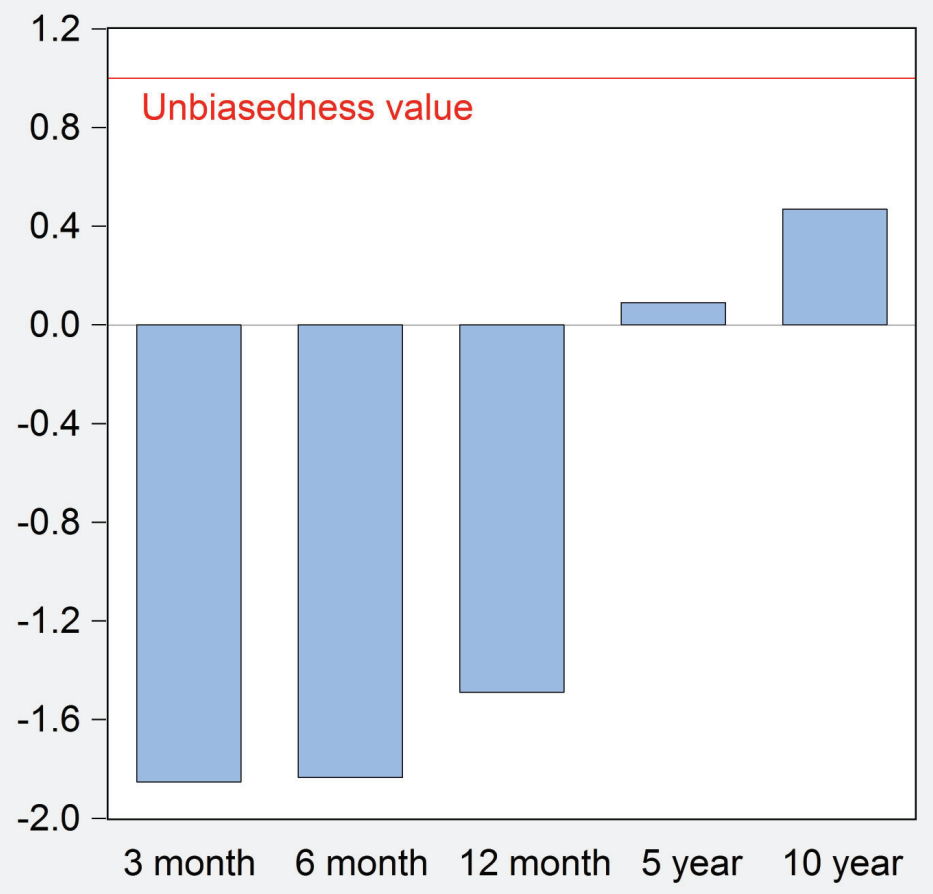

Figure 1: Panel Fama coefficients 1980Q1-2007Q4, unbalanced, with fixed effects

Includes Canada, Germany, Euro, Japan, Switzerland, and UK; excludes Euro for 5 and 10 year horizons. 


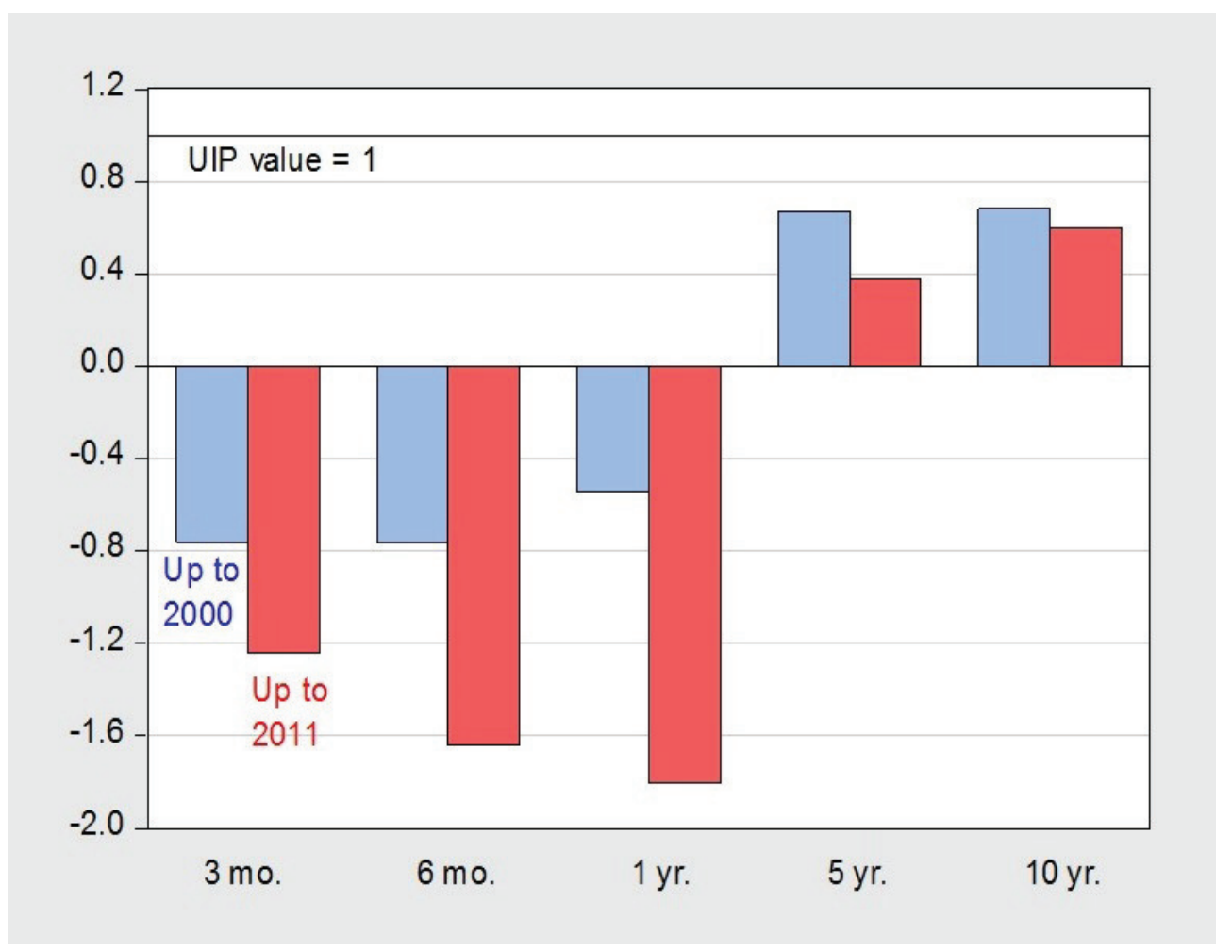

Figure 2: Panel Fama coefficients

Up to 12 months, panel estimates using eurodeposit rates against US\$. For 5 and 10 year, panel estimates using constant yields to maturity. Early sample extends up to 2000Q4, full sample to 2011Q4. Early sample includes mark, yen, pound, franc, lira, and Canadian dollar against dollar for up to 12 months, and excludes lira and franc for 10 year, and also yen for 5 year. Full sample replaces euro legacy currencies with euro and adds in Swiss franc. 

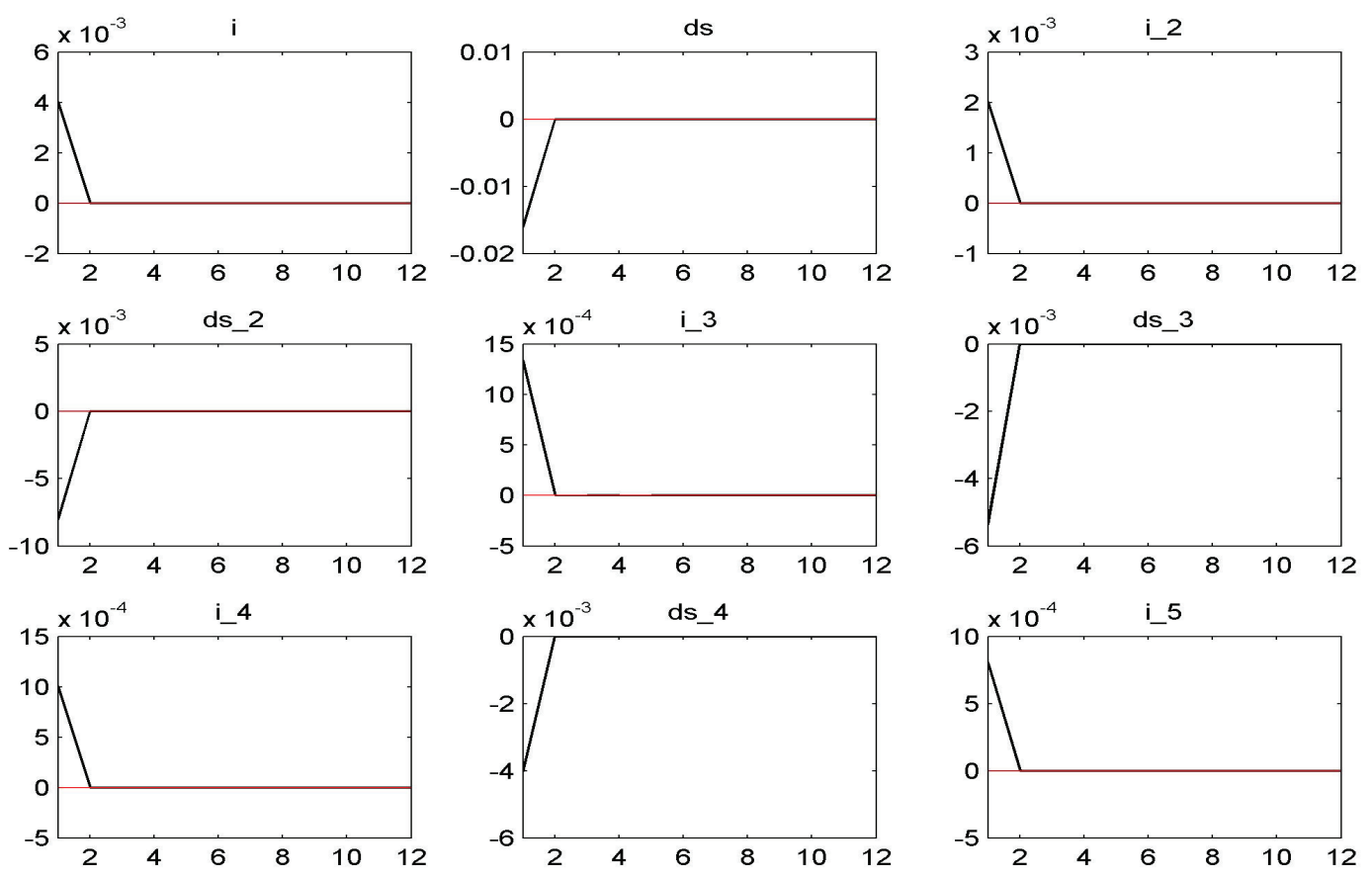

Figure 3: The impulse response function of $e_{i t}$ on macroeconomic variables 

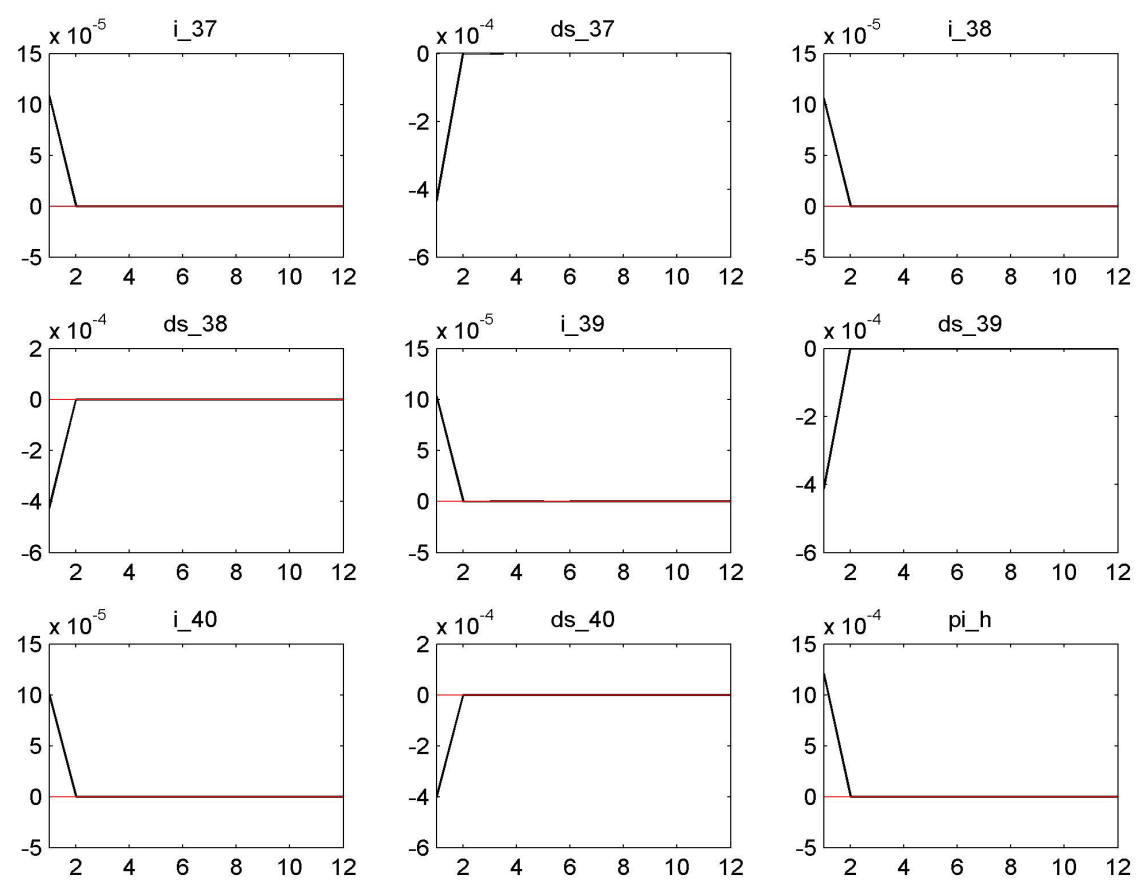

Figure 4: The impulse response function of $e_{i t}$ on macroeconomic variables 

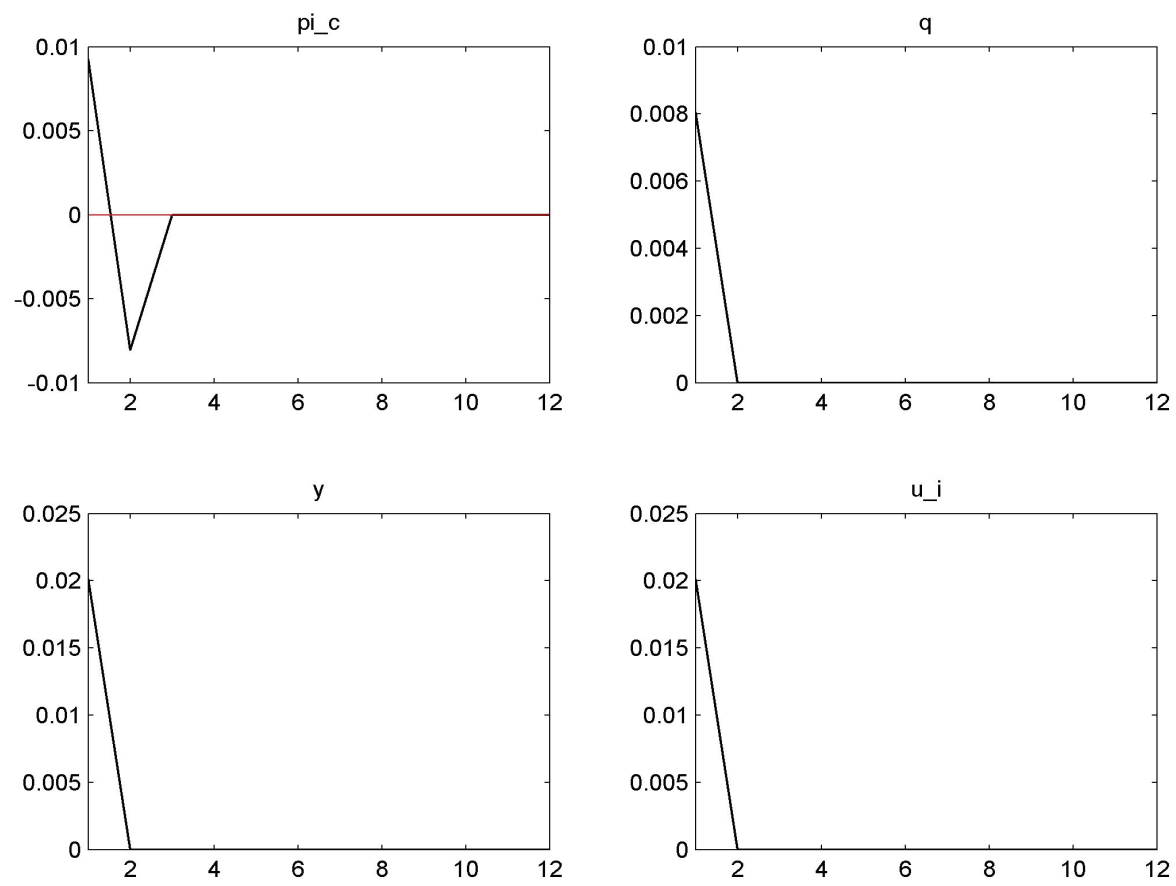

Figure 5: The impulse response function of $e_{i t}$ on macroeconomic variables 

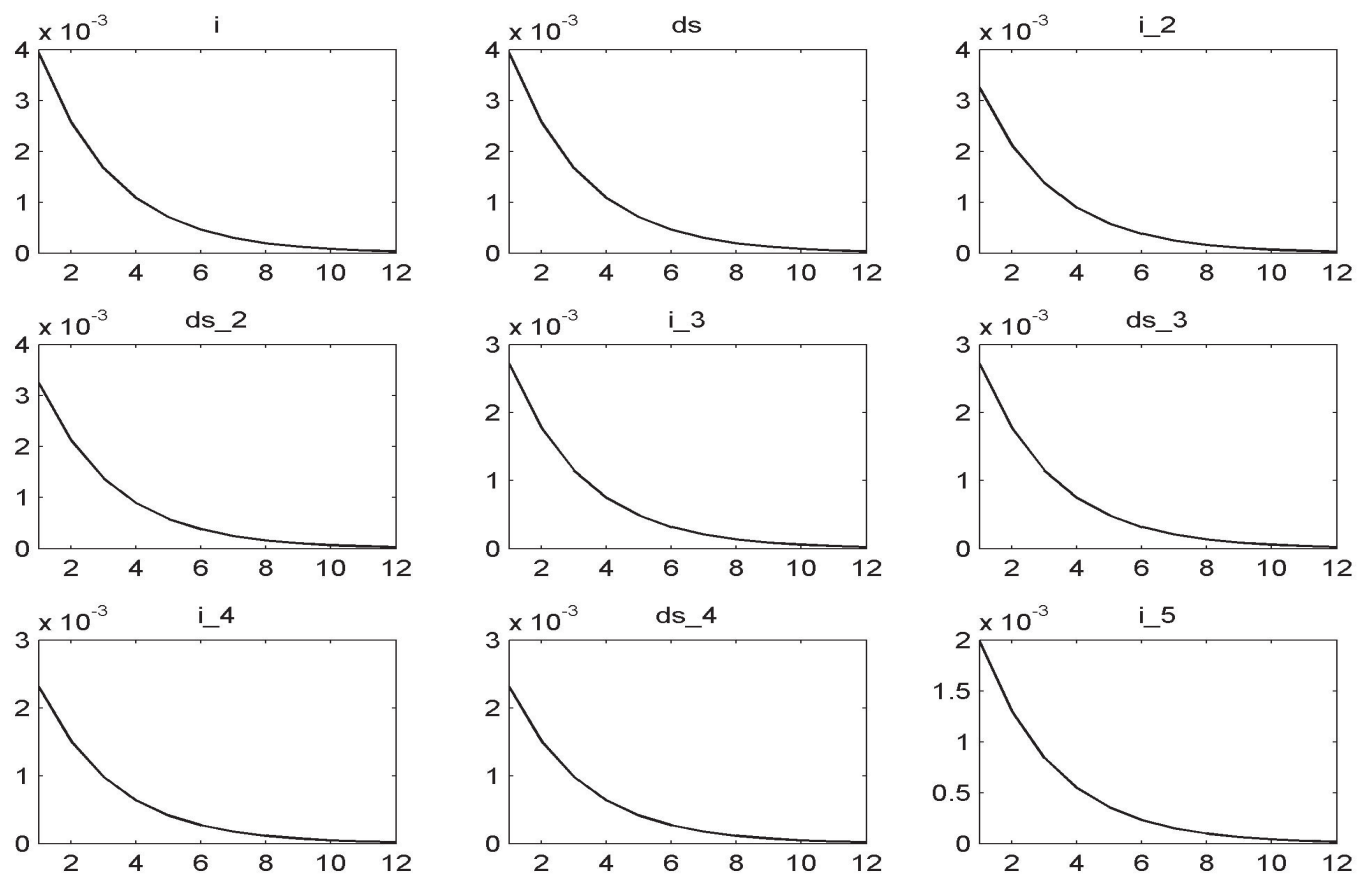

Figure 6: The impulse response function of $e_{c t}$ on macroeconomic variables 

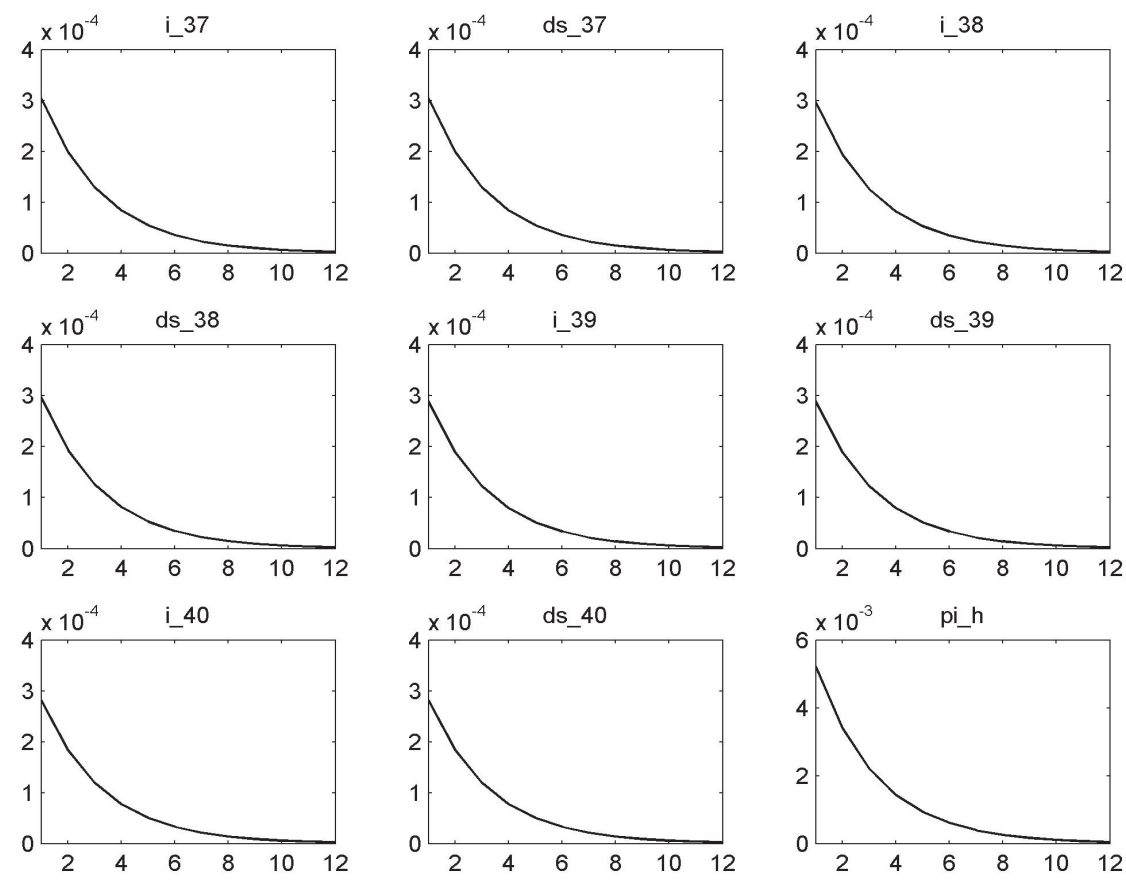

Figure 7: The impulse response function of $e_{c t}$ on macroeconomic variables 

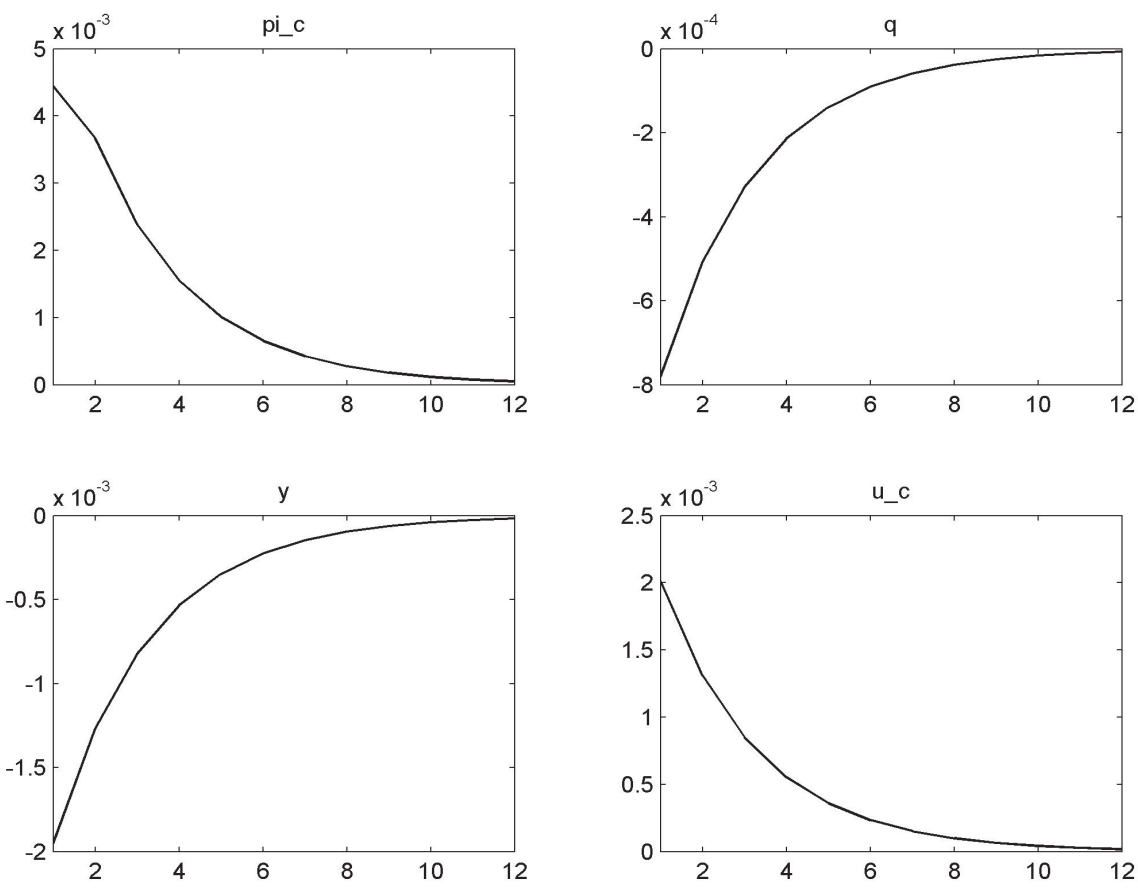

Figure 8: The impulse response function of $e_{c t}$ on macroeconomic variables 

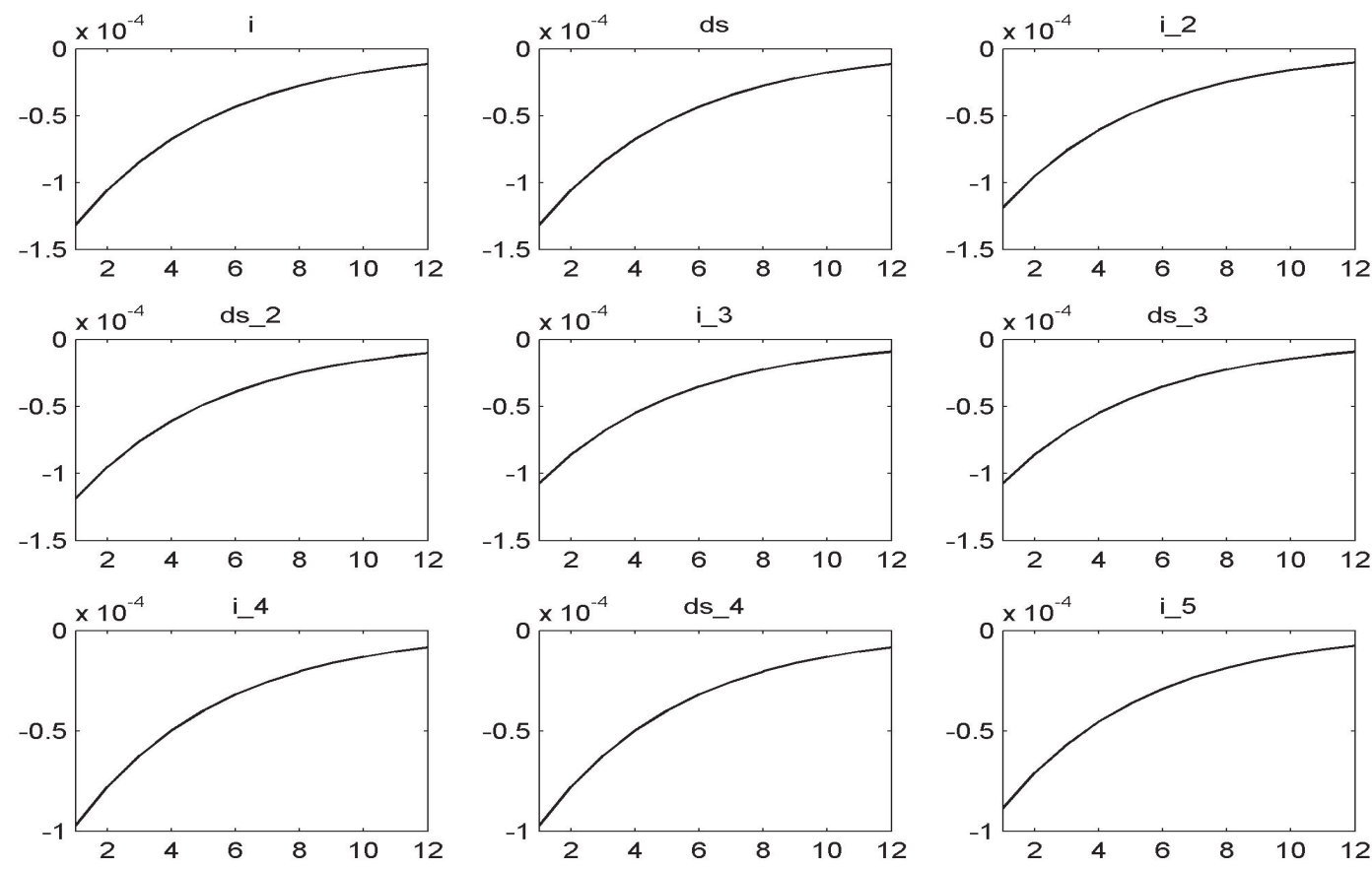

Figure 9: The impulse response function of $e_{m t}$ on macroeconomic variables 

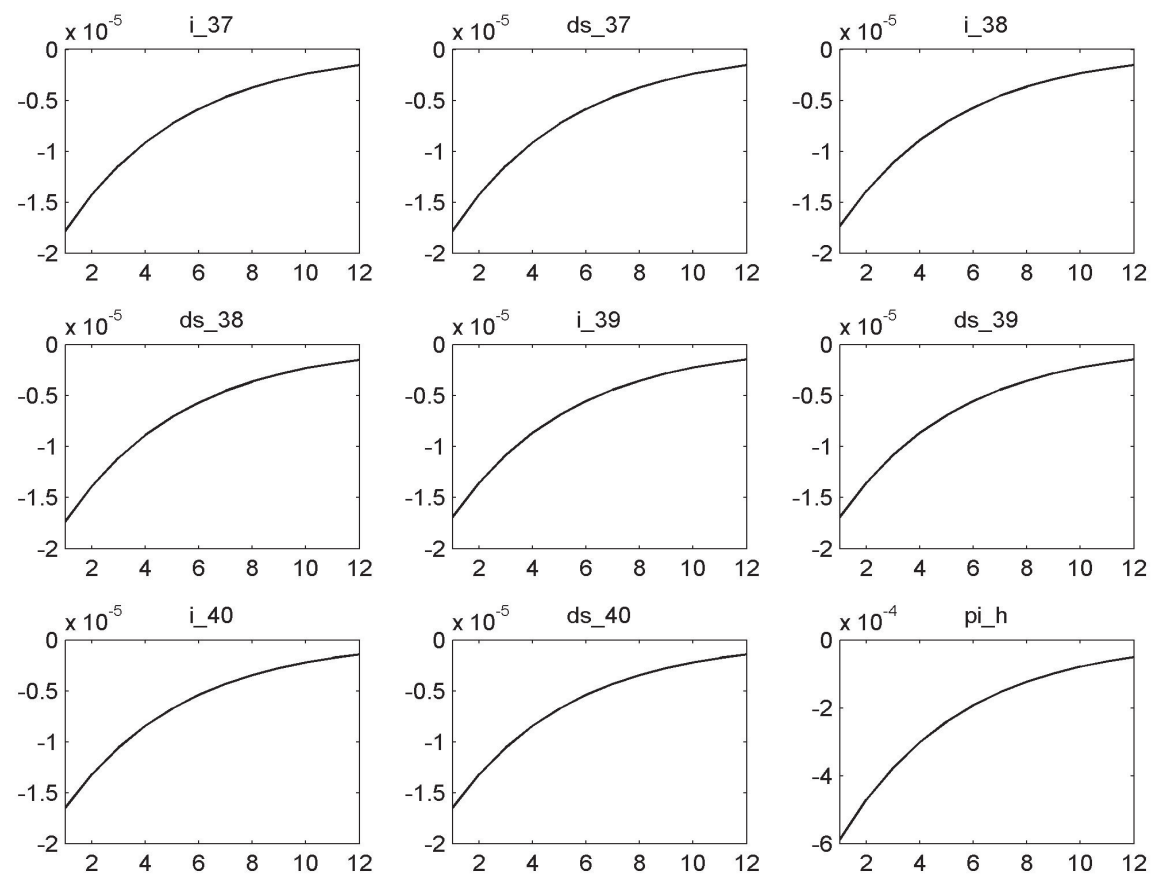

Figure 10: The impulse response function of $e_{m t}$ on macroeconomic variables 

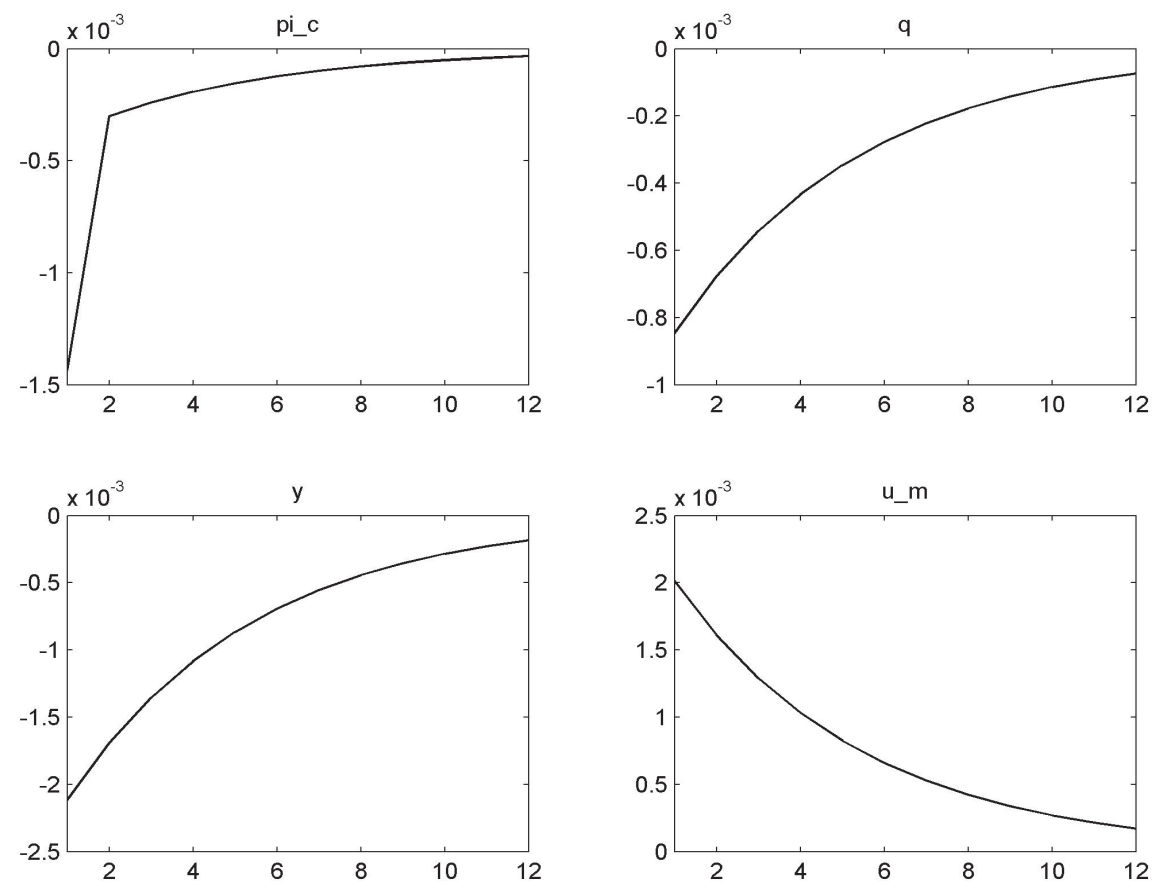

Figure 11: The impulse response function of $e_{m t}$ on macroeconomic variables 


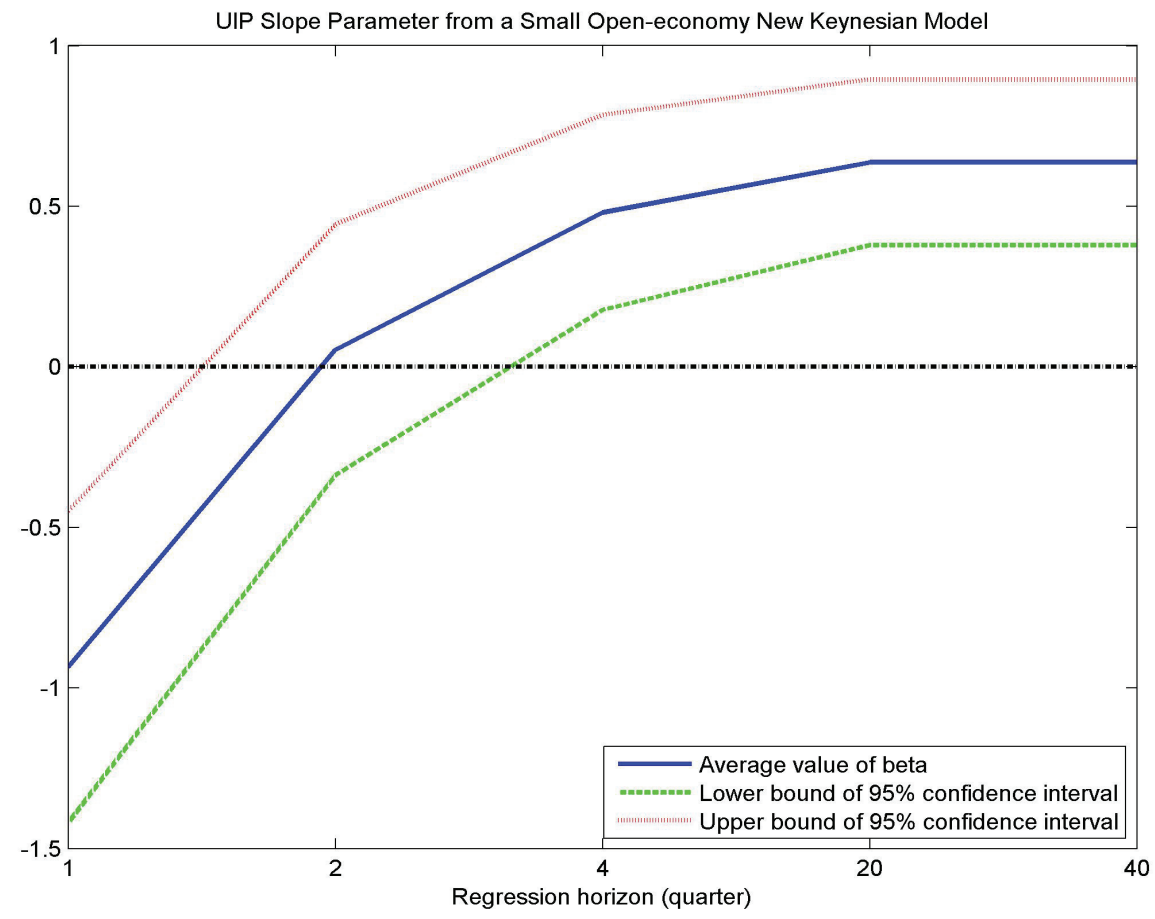

Figure 12: UIP slope parameter from model simulations 


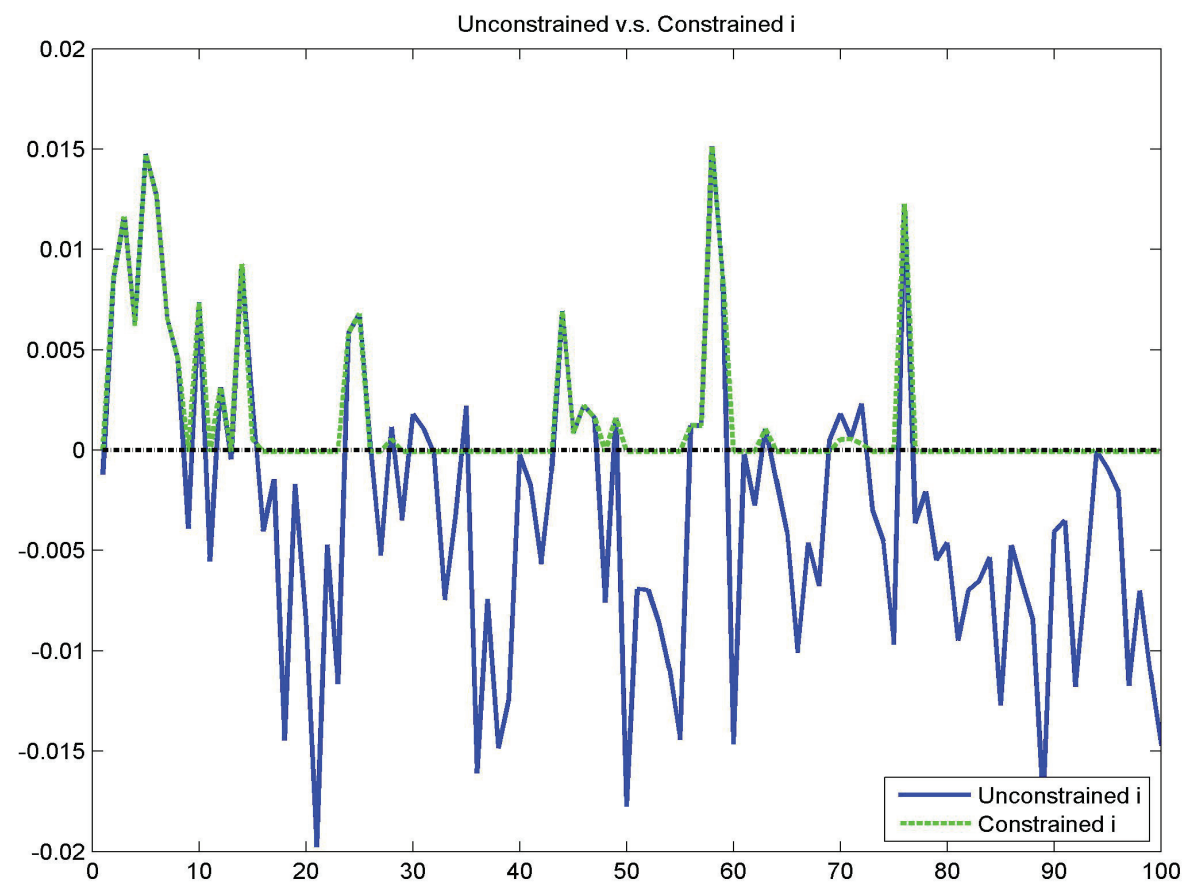

Figure 13: A sample simulation of 100 periods with ZLB 


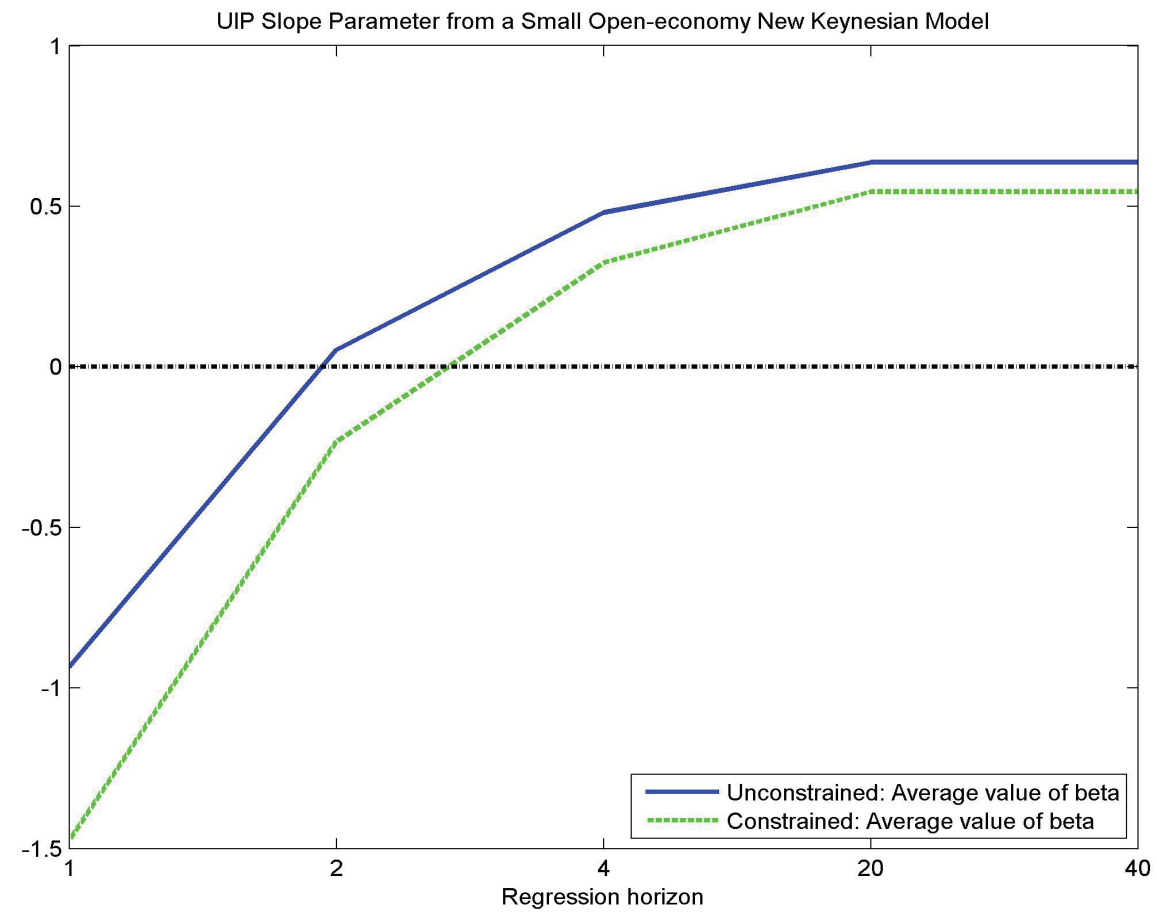

Figure 14: Unconstrained v.s. constrained UIP slope parameters from model simulations 


\section{List of Tables}

1 Variance and C.I. of Japanese interest rates and nominal exchange rate depreciation . 37

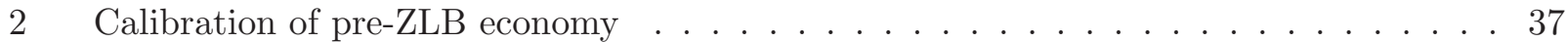


Table 1: Variance and C.I. of Japanese interest rates and nominal exchange rate depreciation

\begin{tabular}{|c|c|c|}
\hline & $s_{t+1}-s_{t}$ & $i_{t}-i_{t}^{*}$ \\
\hline variance & 0.003860 & 0.000690 \\
\hline $90 \%$ CI & {$[0.002928,0.004793]$} & {$[0.000523,0.000857]$} \\
\hline
\end{tabular}

Table 2: Calibration of pre-ZLB economy

\begin{tabular}{|l|l|}
\hline$\omega=0.89$ & probability of not being able to reset price in each period \\
\hline$\beta=0.98$ & domestic discount factor \\
\hline$k=0.0158$ & $k \equiv \frac{(1-\omega)(1-\beta \omega)}{\omega}$ \\
\hline$\gamma=0.5$ & foreign bias \\
\hline$a=1.5$ & elasticity of substitution between domestic and foreign good \\
\hline$\eta=3, \sigma=2$ & CRRA coefficient in utility \\
\hline$\sigma_{\gamma} \equiv \frac{\sigma}{[1-\gamma(1-a \sigma)(2-\gamma)]}$ & \\
\hline$\delta_{\pi}=1.5, \delta_{y}=0.8$ & coefficient of Taylor rule \\
\hline$\rho_{i}=0$ & $\mathrm{AR}(1)$ coefficient of $u_{i}$ \\
\hline$\rho_{c}=0.65$ & $\mathrm{AR}(1)$ coefficient of $u_{c}$ \\
\hline$\rho_{m}=0.8$ & $\mathrm{AR}(1)$ coefficient of $u_{m}$ \\
\hline$e_{i t} \sim \mathrm{N}\left(0,0.02^{2}\right)$ & white noise \\
\hline$e_{c t} \sim \mathrm{N}\left(0,0.002^{2}\right)$ & white noise \\
\hline$e_{m t} \sim \mathrm{N}\left(0,0.002^{2}\right)$ & white noise \\
\hline $\bar{i}=6.7 * 10^{-5}$ & steady state of domestic interest rate \\
\hline
\end{tabular}

